\title{
LA SOLANA DE LAS PILILLAS Y OTROS TESTIMONIOS DE PRODUCCIÓN Y CONSUMO DE VINO EN LA MESETA DE REQUENA-UTIEL
}

\author{
THE SOLANA DE LAS PILILLAS AND OTHER TESTIMONIES OF PRODUCTION AND CONSUMPTION \\ OF WINE IN THE PLATEAU OF REQUENA-UTIEL
}

\author{
ASUNCIÓN MARTÍNEZ VALLE \\ Museo Municipal de Requena
}

\section{INTRODUCCIÓN}

La Meseta de Requena-Utiel está situada en la parte occidental de la provincia de Valencia, a unos $80 \mathrm{~km}$ de la costa mediterránea. Se trata de un altiplano que con orientación NO-SE está rodeado por el norte y el noroeste de sierras pertenecientes al Sistema Ibérico (Molón, Negrete, Montote y Martés) y por el sur y el oeste por la depresión del río Cabriel. Con una forma ligeramente redondeada y una superficie aproximada de $2.100 \mathrm{~km}^{2}$ posee una altitud media de 600 a 700 m s. n. m. en la llanura central que, formada por suelos cuaternarios cubiertos de viñedos, identifica esta comarca limítrofe entre la provincia de Valencia y la comunidad autónoma de Castilla-La Mancha (Fig. 1). La hidrografía se articula en dos cuencas principales, la del río Cabriel por el sur con sus afluentes rambla de Caballero y rambla Albosa, y la del Magro, que atraviesa la llanura central, con el río Madre y la rambla de La Torre y de Ranera como principales aportes. El clima mediterráneo continental y su altitud permiten pocas opciones a la agricultura siendo la vid, y en concreto la variedad Bobal propia de esta comarca, la que mejor se adapta a esta climatología.

La Meseta de Requena-Utiel es un nudo de comunicaciones donde coinciden varias vías naturales que documentadas desde la Antigüedad todavía continúan en uso. Los principales accesos desde la costa seguirían los cursos de los ríos Turia, Xúquer y Magro para, una vez atravesado el altiplano, alcanzar la Meseta Castellana a través de los distintos pasos del río Cabriel; los caminos hacia la Serranía de Cuenca discurrirían por Camporrobles, bordeando la Sierra de Aliaguilla, y Talayuelas, siguiendo la rambla de Ranera. Una tercera vía nos conectaría con Andalucía por el camino de Requena a Almansa que se bifurcaría hacia Alicante, o hacia Xàtiva, por el valle de Montesa (Piqueras, 1997, 86).

Los primeros testimonios de cultivo de vid y consumo de vino en la Meseta de Requena-Utiel no son en sí un hecho destacado, ya que son comparables a otras zonas donde la introducción de la vitis vinifera y la presencia de las ánforas R1 son consecuencia de contactos coloniales (Bonet et alii, 2004, 213). Lo que adquiere un carácter relevante es la temprana producción de vino a una escala comercial (Celestino y Blanquez, 2007) avalada por la fabricación local de contenedores y la capacidad de las infraestructuras dedicadas a su producción. El cultivo de uva se ha documentado por primera vez en niveles de inicio del s. VI a.C. en los Villares de Caudete de las Fuentes, lugar que se

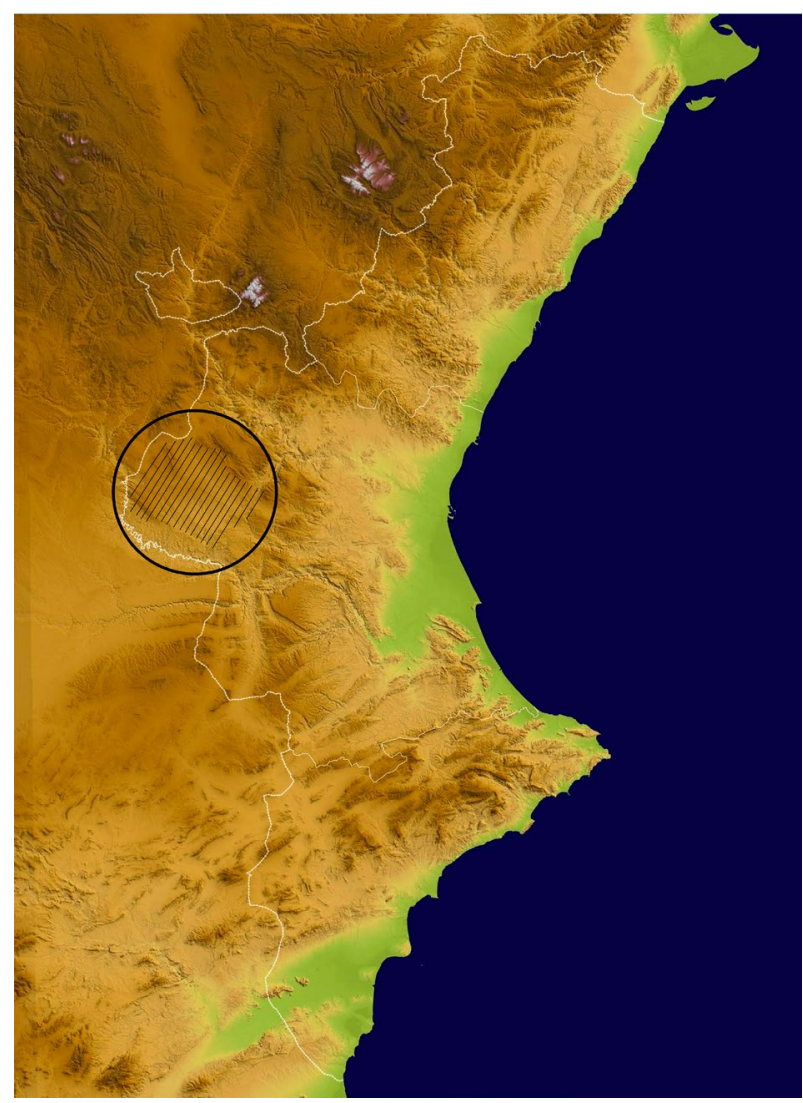

Figura 1: Situación de la meseta de Requena-Utiel en el contexto de la Comunidad Valenciana. 


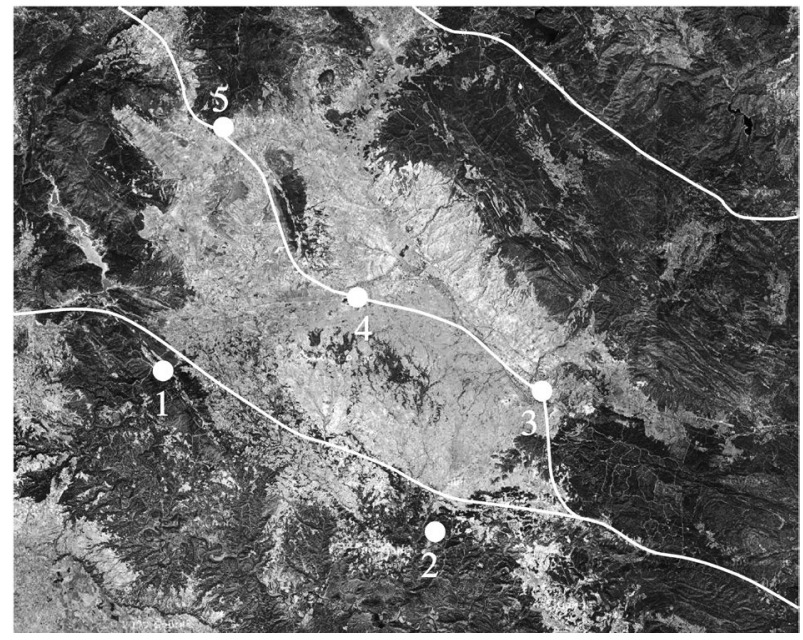

Figura 2: La Meseta de Requena-Utiel con la ubicación de Casillas del Cura (1); Solana de las Pilillas (2); la Villa de Requena (3); Caudete de las Fuentes (4); Molón de Camporrobles (5) y las principales vías de penetración a la comarca en el s. VII a.C.

identifica con la ciudad ibérica de Kelin, donde se han recuperado escasas semillas carbonizadas de vitis vinifera que van incrementando su presencia a partir de los siglos V-IV a.C. (Mata et alii, 1997, 44). La presencia de pepitas de uva puede ser indicativa de producción de vino, pero también de su consumo como fruta fresca o seca; en el caso de Kelin (Caudete de las Fuentes) no se ha producido la asociación de vitis vinifera con estructuras para el pisado de la uva, pues hasta la actualidad no se han documentado lagares, pero es un testimonio que corrobora cultivo de uva en un momento en que ya se está produciendo vino en la Solana de las Pilillas (Requena).

El consumo de vino en los yacimientos del Hierro Antiguo se evidencia por las ánforas R.1 que procedentes de las factorías fenicias del sur peninsular penetran desde la costa hacia el interior principalmente por el corredor del Magro y a través del valle de Hortunas. Las primeras importaciones llegan a poblados como la Villa de Requena, Kelin en los Villares de Caudete de las Fuentes o el Molón de Camporrobles, que situados junto a importantes ejes viarios presentan un poblamiento estable desde el s. VII a.C. con indicios de ocupaciones anteriores (Fig. 2). A principios del s. VI a.C. aumenta el porcentaje de estas importaciones alcanzando el 55\% del total de los cuarenta yacimientos inventariados (Moreno, 2011, 51).

Las primeras evidencias de producción de vino proceden de la Solana de las Pilillas donde se elaboraba en lagares rupestres desde inicios del s. VI a.C. La fabricación de ánforas para los procesos de fermentación está bien documentada en Casillas del Cura (Venta del Moro) desde el s. VI a.C., con un porcentaje superior al $10 \%$ del total de la producción del alfar (Martínez Valle et alii, 2000; Martínez Valle y Hortelano, 2012). Si las ánforas de importación documentan el consumo, la fabricación local de estos contenedores es un hecho que tiene singular importancia para atestiguar la producción de vino y su almacenamiento; la tipología es indicativa no solo de la cronología de inicio, sino también de las influencias o la procedencia de la transmisión tecnológica (Alexis, 2013, 126).

\section{EL INICIO DE LA VITICULTURA EN LOS LA- GARES RUPESTRES DE LA SOLANA DE LAS PILILLAS}

La Solana de las Pilillas está situada en el margen derecho de la rambla de Los Morenos, próximo a la pedanía de Los Duques, en el llano del Campo Arcís (Requena), una cuenca formada sobre la superficie de un antiguo fondo lagunar donde se han depositado sedimentos terciarios y cuaternarios óptimos para el cultivo de la vid. Las ramblas de Los Morenos y de La Alcantarilla se reparten, casi a partes iguales, el drenaje del llano de Campo Arcís por medio de múltiples ramificaciones que han labrado una erosión de badlands con paredes casi verticales de 4 a $10 \mathrm{~m}$ de profundidad, sin apenas transición con el llano. Estas ramblas forman parte de la subcuenca de la rambla de Caballero, tributaria del río Cabriel que se une al Júcar en Cofrentes y desemboca en el Mediterráneo en las proximidades de Cullera.

El centro productor de Las Pilillas se localiza en una ladera orientada al SE, de algo más de $60 \mathrm{~m}$ de desnivel, a unos $530 \mathrm{~m}$ de altura y a menos de 100 $\mathrm{m}$ de la rambla de Los Morenos; por debajo del yacimiento hay un pequeño glacis cultivado que limita con el fuerte encajamiento de unos $30 \mathrm{~m}$ de la rambla. A unos $500 \mathrm{~m}$ al NE se encuentra la fuente de Los Morenos, una de las más copiosas de la comarca y que es el principal afloramiento de agua de esta rambla (Ruiz Pérez, 2012, 46). En toda la extensión de la ladera se localizan grandes bloques calizos desprendidos de la cima que han condicionado la distribución espacial del yacimiento. Cuatro de estos bloques se utilizaron para labrar los lagares y otros fueron utilizados para adosar estructuras y cimentar los muros que configuran este complejo productor de vino.

Todas las evidencias arqueológicas del yacimiento, lagares y estructuras asociadas, se localizan entre la parte baja de la ladera y el cortado donde se encaja la rambla. Los cuatro lagares están distribuidos en torno a un camino paralelo a la rambla y están separados entre 22 y $100 \mathrm{~m}$ de distancia ${ }^{1}$ (Fig. 3). El acceso se realiza a través de un camino próximo a la fuente de Los Morenos y en diversos tramos de este camino se observan carrileras en la roca y entalladuras para permitir el paso de los

1. Juan Piqueras Haba, catedrático de geografía de la Universidad de Valencia nacido en Campo Arcís, nos comentó que se destruyeron dos lagares más cuando se pusieron en cultivo los campos que están junto al yacimiento a inicios del siglo pasado. 


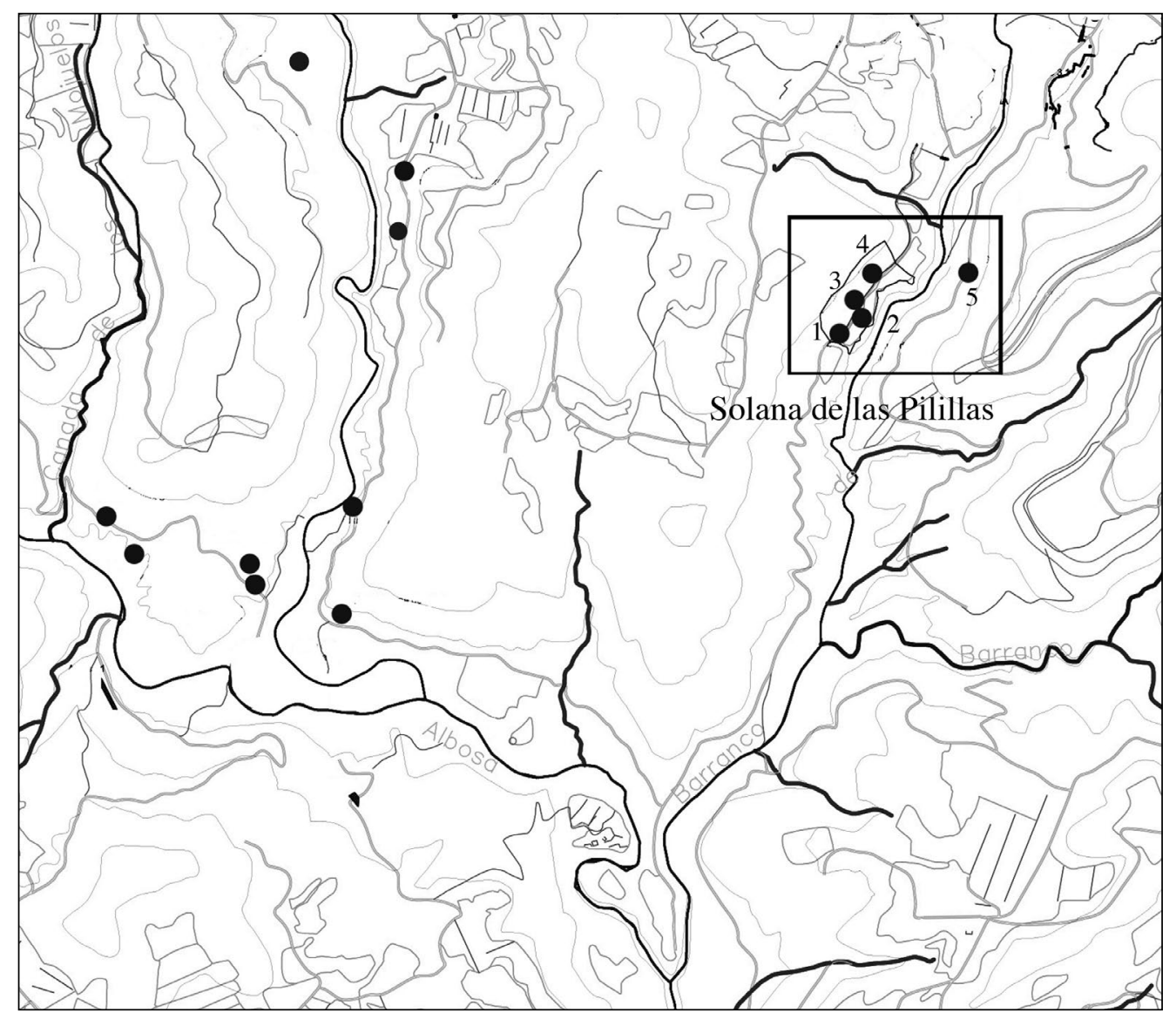

Figura 3: Imagen de las ramblas de los Morenos y Alcantarilla con la situación de los lagares y almazaras rupestres. En el cuadro la Solana de las Pilillas y la Pililla del Salto (5).

carros; en los tramos donde no aflora la roca natural, se conservan empedrados realizados también para facilitar la comunicación y donde el camino se amplia se aprecian dobles carrileras. Los caminos documentan la comunicación con el llano y unirían el centro productor de Las Pilillas con la red de asentamientos próximos que formarían parte de la organización de todo este espacio que articula la rambla y que se vincula con el cultivo de la vid y la producción de vino (Fig. 4).

En 1990 visitamos por primera vez la Solana de las Pilillas para su inclusión en el Inventario de Yacimientos Arqueológicos de la Comunidad Valenciana ${ }^{2}$. En 1999, desde la Universidad de Valencia y dentro del proyecto de estudio del territorio ibérico de la comar$\mathrm{ca}^{3}$ se realizó una limpieza parcial de los lagares para su presentación en la «III Reunió sobre Economía en el Món Ibèric» que se celebró en Valencia, proponiendo para este conjunto una datación del Ibérico Pleno

2. La fichas del primer inventario del término municipal de Requena fueron realizadas por Rafael y Asunción Martínez Valle. Agradecemos a Antonio López Haba el habernos mostrado la Solana de las Pilillas y otros muchos yacimientos del término municipal de Requena.

3. El proyecto de investigación «El poblamiento ibérico en la Plana de Utiel» ha estado dirigido por Consuelo Mata Parreño.

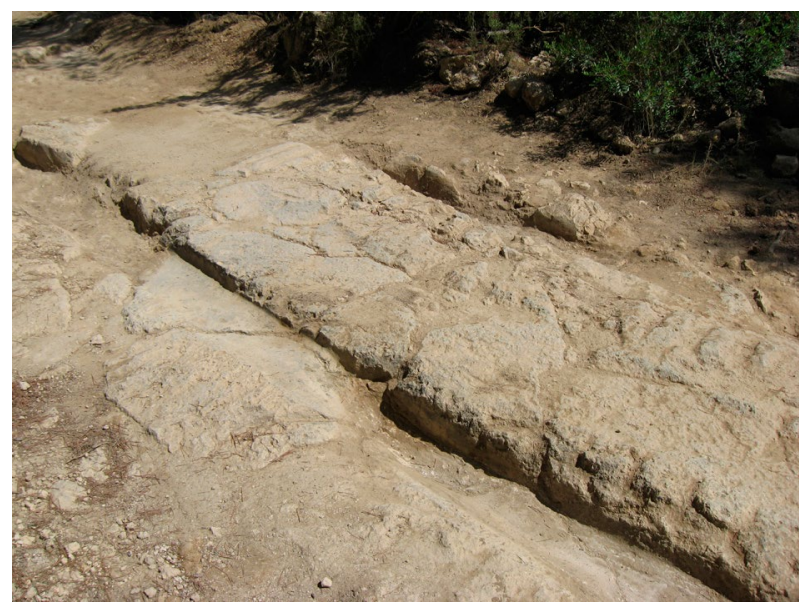

Figura 4: Carriladas en el camino a la Solana de las Pilillas.

(Pérez Jordá, 2000, 60). En el año 2008 se inició la excavación arqueológica del yacimiento para acceder al nivel de ocupación de época ibérica y musealizar el conjunto, dentro del marco del estudio y recuperación del «Paisaje Cultural de la vid y el vino en La Meseta de Requena-Utiel» ${ }^{4}$. A partir de ese momento y

4. Este proyecto intenta recuperar los diferentes testimonios de patrimonio material e inmaterial de la «Cultura del Vino» 


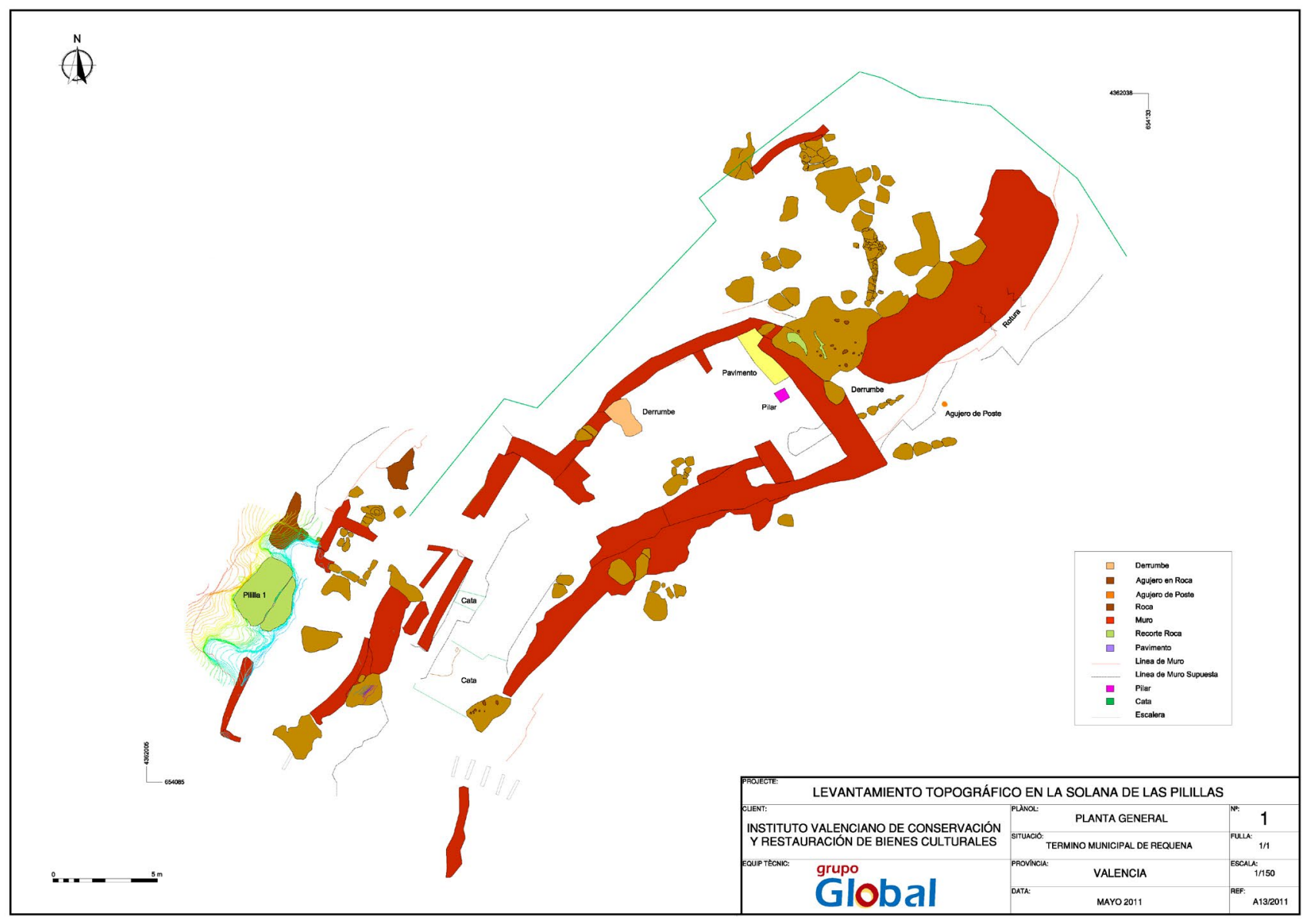

Figura 5: Vista del Sector Norte del yacimiento.

hasta la actualidad se han realizado cuatro campañas de excavación, de varios meses en 2009, 2010, 2011 (Martínez Valle y Maronda, 2012), y durante todo el año 2012, que se ha estado trabajando con un Taller de Empleo del SERVEF que ha desarrollado un módulo de arqueología y otro de restauración ${ }^{5}$.

A pesar de las campañas realizadas la información disponible sobre el yacimiento es parcial, ya que solamente se ha trabajado en extensión en el Sector Norte, en el entorno del lagar número 4 (Fig. 5). La excavación nos ha permitido definir las características generales del yacimiento y recuperar el material cerámico que asociado a la elaboración del vino nos ha aportado una cronología contrastada. Debido a la

desde la antigüedad para la elaboración de un expediente de «Paisaje Cultural de la vid y el vino» para declaración de UNESCO. Los promotores del proyecto han sido el Instituto Valenciano de Conservación y Restauración de Bienes Culturales de la Generalitat Valenciana (IVCR), el Ayuntamiento de Requena y la Mancomunidad del Interior de la Tierra del Vino y coodirigen este proyecto Carmen Pérez García y Asunción Martínez Valle.

5. El taller de empleo «Musealización de la Solana de las Pilillas» ha estado promovido por el Instituto Valenciano de Conservación y Restauración de Bienes Culturales de la Generalitat Valenciana y financiado con fondos europeos. gran pendiente existente, todo el espacio se organizó por medio de muros de aterrazamiento que conforman plataformas transitables. El muro más externo y que delimita el complejo conserva en varios tramos una anchura aproximada de $2 \mathrm{~m}$ y un muro curvo semicircular en el camino y junto a la bodega da la apariencia de ser torreón, dando al conjunto el aspecto de un recinto amurallado. El tamaño del complejo de las Pilillas y la calidad de sus estructuras permite afirmar que fue construido para rentabilizar la producción de vino durante un largo periodo de tiempo. Las características de los lagares están condicionadas por el tamaño y la forma de los bloques de piedra en que se tallaron y por las similitudes que presentan todos parecen pertenecer a un mismo momento cronológico.

Lagar 1: Este lagar está tallado sobre un bloque de 4,1 x $2 \mathrm{~m}$, está situado a la derecha del camino y a media ladera, sobre una pequeña elevación. La plataforma superior es de planta rectangular de 2,1 x 1,2 m y está enmarcada por un reborde con una anchura entre 15 y $20 \mathrm{~cm}$ y una altura que varía entre 20 y $30 \mathrm{~cm}$, en la que se excavaron una serie de orificios circulares para el anclaje de los postes que cubrirían la estructura. La cubeta inferior, de planta rectangular, está tallada respetando un reborde de $15 \mathrm{~cm}$ de anchura, actualmente roto en su ángulo norte (Fig. 6); la profundidad de esta 


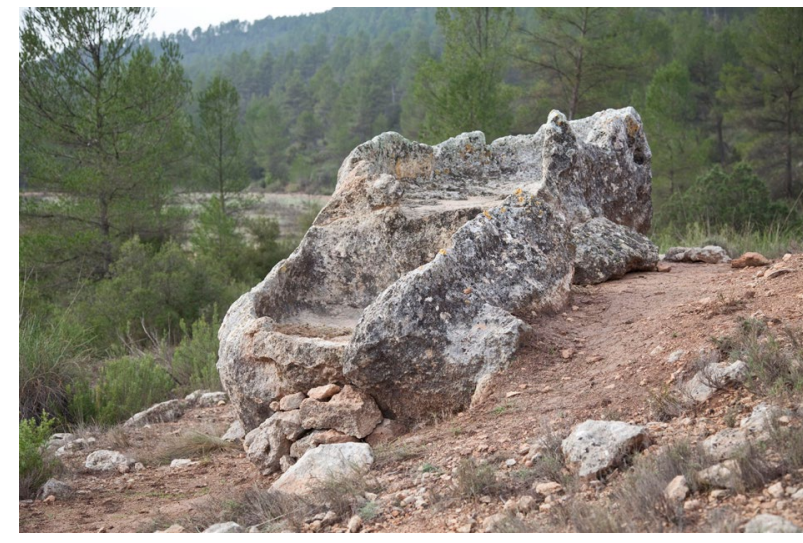

Figura 6: Lagar 1 de la Solana de las Pilillas.

es de $30 \mathrm{~cm}$ y el desnivel entre la base de la plataforma y el de la cubeta es de $65 \mathrm{~cm}$. La comunicación entre ambas cubetas se realiza mediante un orificio tallado en la base de la plataforma superior. Por la parte posterior del lagar se puede ver un canal de sección semicircular junto al hueco de anclaje de un poste, que se encuentra muy erosionado por rozamiento, que permite intuir alguna estructura que por medio de cuerdas sustentaría una prensa. La capacidad aproximada para la recogida del mosto sería de aproximadamente unos 360 litros.

Lagar 2: Este lagar se encuentra junto al actual camino y está tallado en un bloque de aproximadamente $3,5 \times 3,2 \mathrm{~m}$. La plataforma superior presenta una planta más o menos rectangular, de $2,36 \times 1,7 \mathrm{~m}$, y está rodeada por un reborde que también presenta una serie de orificios en su lado sur (Fig. 7). La cubeta inferior está rota en su extremo oeste pero en la limpieza y desbroce del entorno del lagar se recuperaron los fragmentos que faltaban y ya se han reintegrado algunos de ellos. Esta cubeta tendría una planta también rectangular de $2 \times 0,9 \mathrm{~m}$ y una profundidad de $66 \mathrm{~cm}$, lo que daría una capacidad aproximada para unos 1000 litros de mosto. El desnivel entre la base de cada una de las cubetas sería de $60 \mathrm{~cm}$.

Todo el borde de la cubeta superior presenta una acanaladura de sección semicircular que podría servir para proteger la estructura tras su utilización.

Lagar 3: Este lagar está tallado en un bloque de aproximadamente 3,7 x 2,1 m. La plataforma superior presenta una planta más o menos ovalada, de 2,3 x 1,5 m, y una serie de agujeros circulares que la rodean, muy bien definidos y conservados, y que servirían para sustentar una techumbre de protección y alguna viga que facilitaría el proceso de pisado. La cubeta inferior tiene una planta casi rectangular, de 1,6 x 0,4 m, y una profundidad de $50 \mathrm{~cm}$, lo que daría una capacidad para unos 320 litros. El desnivel entre las dos cubetas es de $89 \mathrm{~cm}$ (Fig. 8).

En la parte posterior del lagar encontramos el mismo sistema de sujeción de una prensa que el definido en el lagar $n^{\circ} 1$ en el que también se aprecia la erosión interna del canal por el rozamiento de cuerdas.

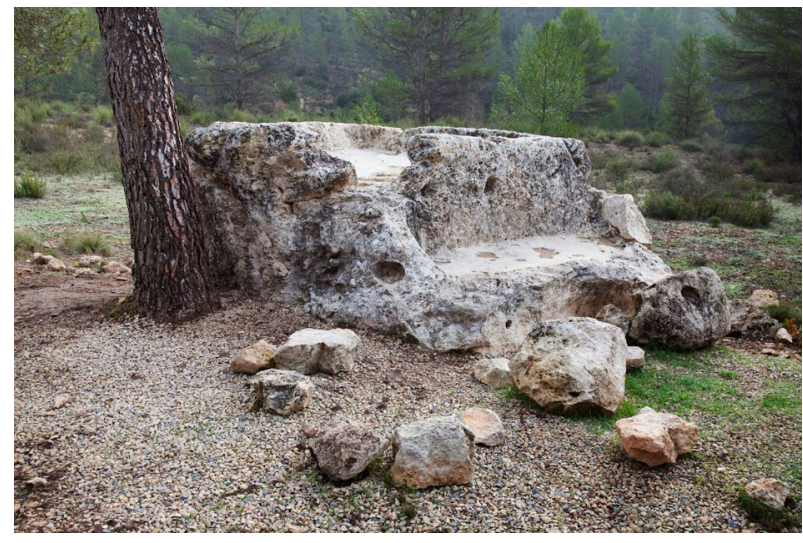

Figura 7: Lagar 2 de la Solana de las Pilillas.

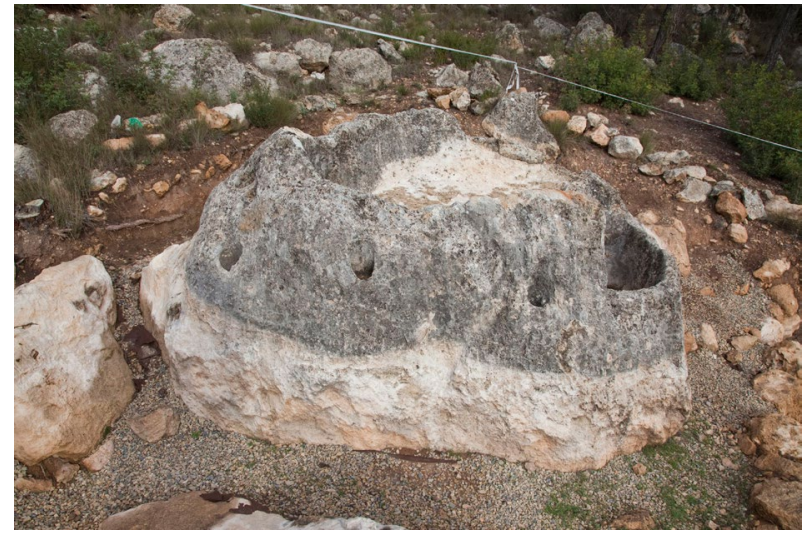

Figura 8: Lagar 3 de la Solana de las Pilillas.

Lagar 4: Tallado sobre un gran bloque de 4,1 x $5 \mathrm{~m}$ es el más grande y mejor conservado del conjunto de Las Pilillas. La plataforma superior es de planta más o menos rectangular, mide aproximadamente 2,6 x 1,46 $\mathrm{m}$ y presenta una profundidad de $30 \mathrm{~cm}$. En la parte posterior tiene una pared vertical de $1,70 \mathrm{~m}$ de altura, en la que se han abierto dos orificios circulares de unos $40 \mathrm{~cm}$ de diámetro y $50 \mathrm{~cm}$ de profundidad, que podrían estar relacionados con el anclaje de las vigas de una prensa de contrapeso.

La plataforma superior comunica con una cubeta inferior mediante dos orificios circulares abiertos en la base; tiene una medida de $2,8 \times 0,8 \mathrm{~m}$, con una profundidad que oscila entre 20 y $50 \mathrm{~cm}$, lo que daría una capacidad aproximada de 400 litros. El desnivel entre las dos cubetas es de $50 \mathrm{~cm}$. En este lagar, cuando se accedió al nivel de ocupación se documentó como en la base del bloque, en las partes cóncavas más débiles se acoplaron láminas gruesas de piedra que trabadas con tierra, piedras medianas y cal regularizaban el bloque, dándole una mayor solidez (Fig. 9).

En la campaña del 2010, a unos $30 \mathrm{~m}$ del lagar, se localizó un bloque de gran tamaño de características similares a los que se utilizaron para excavar los lagares. En la parte más elevada se conserva un pequeño canal para evacuar líquidos y algunos agujeros de poste, lo que nos hizo pensar en la posibilidad de que se tratase de un nuevo lagar parcialmente cubierto 

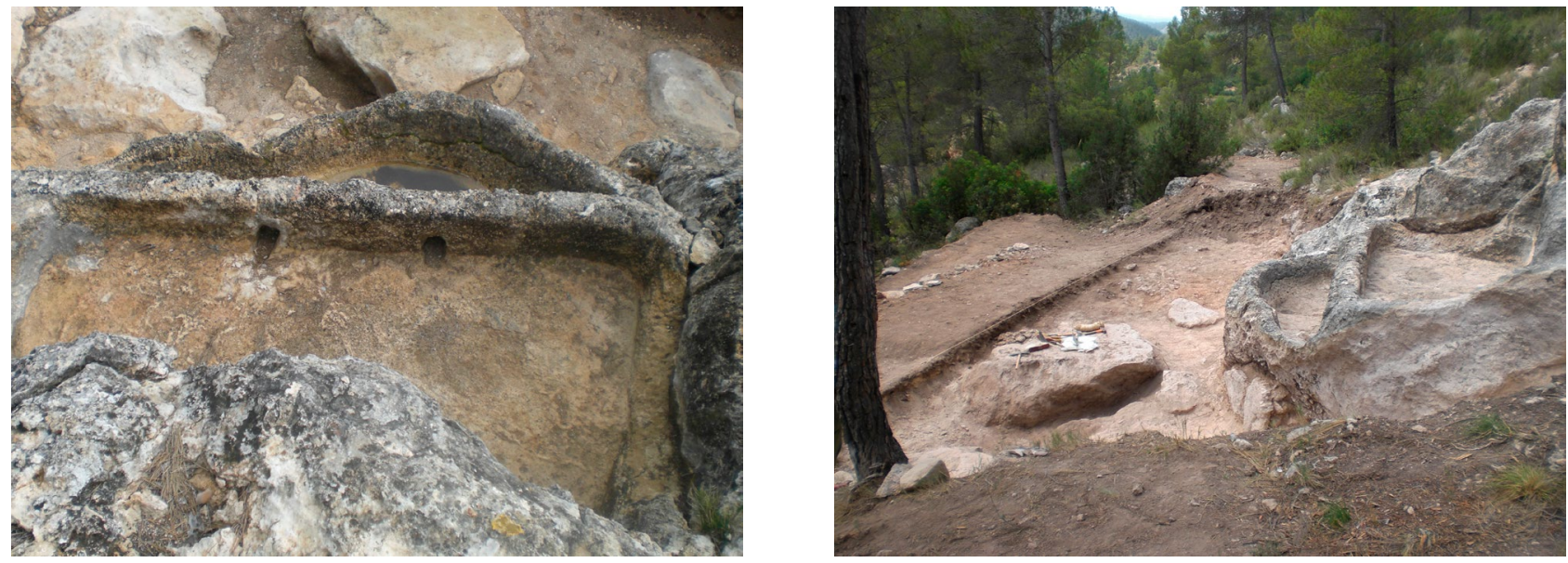

Figura 9: Lagar 4 de la Solana de las Pilillas.

por el sedimento de la ladera. Cuando se realizó la excavación del entorno se pudo ver que, debido a su tamaño había sido parcialmente tallado para articular varias estructuras. Por su lado meridional y adosado a él se construyó un gran muro circular de $10 \mathrm{~m}$ de longitud y una anchura superior a los $3 \mathrm{~m}$, que conforma la base de lo que debió de ser una «media torre» junto al camino y que en sentido ascendente permitía, por medio de una rampa, acceder al espacio interior en una cota superior. En el espacio interno se documentaron varios niveles muy arrasados y departamentos de planta semicircular, realizados mediante muretes de mampostería que tendrían un alzado de tapial, cuyos restos se recuperaron deshechos en el interior del recinto, correspondiendo todo este espacio a una zona de almacén o habitación ocasional. La excavación de la parte posterior del espacio interno de la torre y del pasillo que comunica con el lagar ha quedado por concluir hasta la próxima campaña.

Al este del bloque hay un muro de mampuestos adosado a la ladera, que tiene una longitud de $15 \mathrm{~m}$ y conserva un alzado superior a los $2 \mathrm{~m}$. La base del muro la forman grandes piedras de aspecto ciclópeo, mientras que las hiladas superiores son de menor tamaño. Con

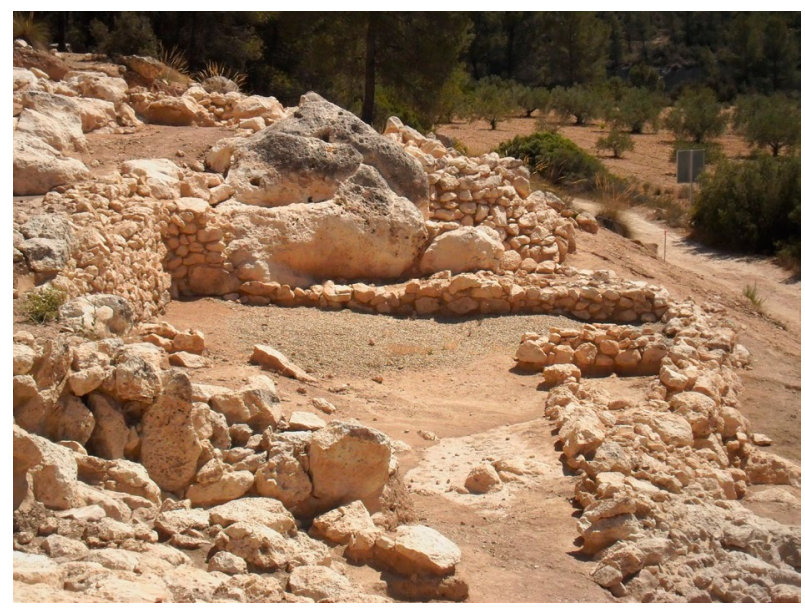

Figura 10: Bodega asociada al lagar 4 de la Solana de las Pilillas. una trayectoria paralela se levanta otro muro de dos caras junto al camino que en algunos puntos superó los $2 \mathrm{~m}$. A partir del muro del talud y mediante muretes transversales se articulan diversos espacios de planta rectangular que configuran la bodega asociada al lagar (Fig. 10). Todo el sector excavado del yacimiento se organiza por medio de terrazas que permiten el acceso al lagar y la comunicación con la bodega con pequeñas habitaciones que servirían de almacenes y espacios anexos. La gran pendiente existente hace que los muros que configuran los diferentes espacios se adosen a la ladera y sirvan también de hormas de contención de las terrazas por las que podía se transitar.

La excavación realizada permite intuir el funcionamiento del complejo productor de vino de la Solana de las Pilillas emplazado en un lugar elegido por sus condiciones óptimas para el cultivo de la uva y la elaboración del vino. Con buena orientación SE y protegido por montañas que delimitan la rambla, posee un microclima más benigno que en la meseta central. $\mathrm{Su}$ localización a media ladera facilitaría los procesos de decantación; los afloramientos calizos, con bloques lo suficientemente grandes para tallar los lagares, permitirían una rentabilidad superior al trabajo invertido en la construcción de todo este complejo. Por otra parte las terrazas fluviales junto a la rambla podrían haberse utilizado para la plantación de viñedos aprovechando para el riego el agua procedente de la fuente de Los Morenos. Los cambios geomorfológicos producidos desde época ibérica explicarían la localización de un muro, seccionado por la acción erosiva de la rambla, al que se adosan arenas fluviales, que podría marcar el nivel más alto de la rambla en época ibérica y que correspondería a un punto de abastecimiento de agua al tratarse del acceso más cercano al yacimiento (Ruiz Pérez, 2012, 52).

En toda la extensión excavada, aproximadamente $900 \mathrm{~m}^{2}$, no se han recuperado restos óseos, ni basureros, ni hogares que puedan indicar una ocupación continuada de este sector que identificamos con un área exclusiva de trabajo. Lo que sí se ha recuperado es abundante material cerámico, en muchos casos desplazado por la gran acción erosiva que ha sufrido la pendiente. De las 

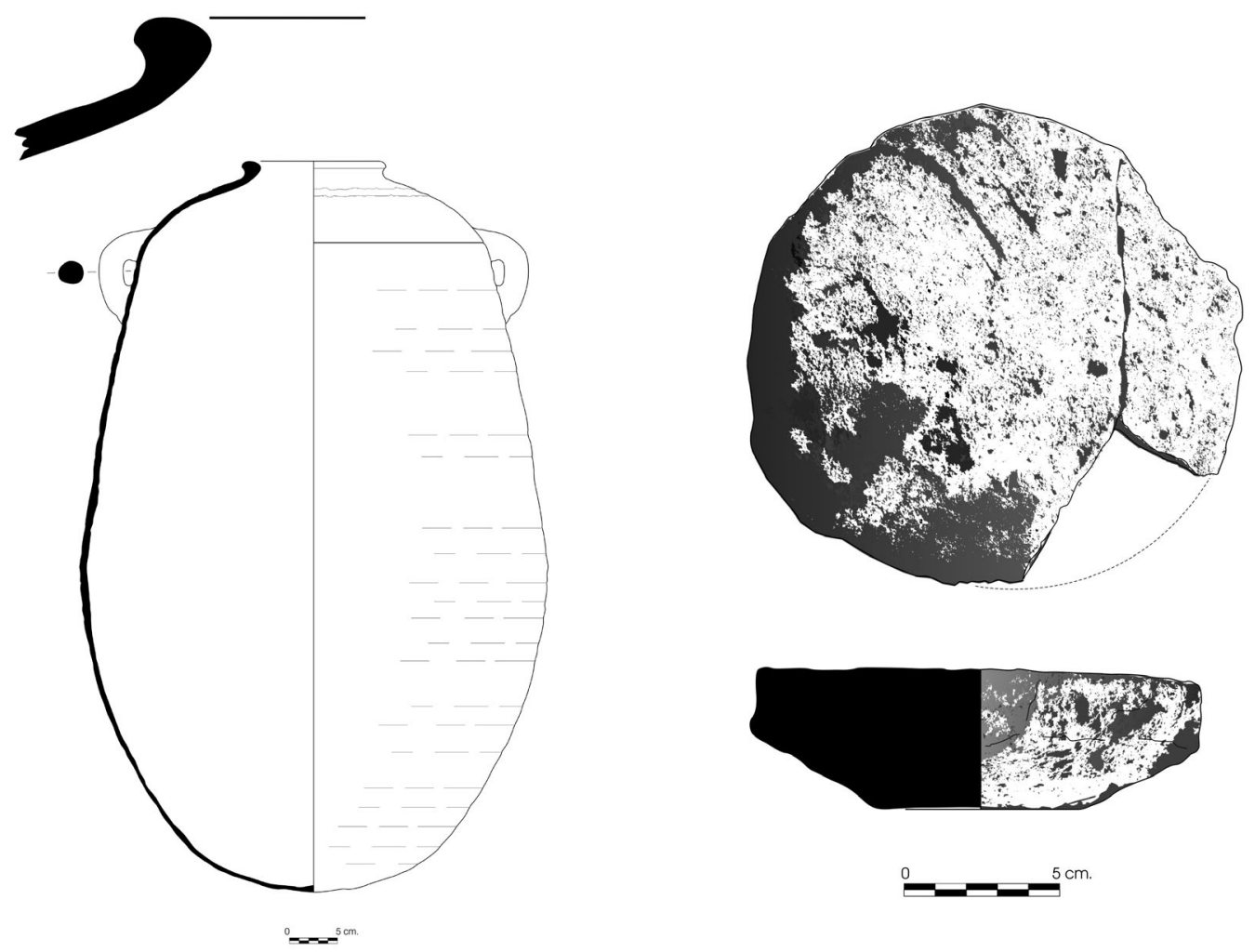

Figura 11: Ánfora ovoide de las Pilillas (SdP 1205) y tapadera de caliza local hallada en la bodega.

cerámicas recuperadas durante las campañas de excavación, destacamos las ánforas como un exponente de la elaboración del vino, ya que son estos recipientes los que se utilizaron en las Pilillas para los procesos de fermentación. Con los numerosos fragmentos hallados en la zona de la bodega y junto al lagar se han podido reconstruir, hasta el momento, un ánfora completa y dos a las que faltan las bases. Nuevas ánforas se van configurando a partir de los bordes, las bases y los fragmentos de galbo que se van uniendo en el laboratorio. Junto con las ánforas, numerosas tapaderas talladas en roca caliza local confirman la hipótesis de que en este espacio se realizaba el proceso de vinificación.

Gracias al trabajo de montaje y restauración de los fragmentos que vamos recuperando podemos afirmar que los tipos anfóricos de Las Pilillas son una derivación de los modelos fenicios, particularmente de la R.1. El recuperar un ánfora completa nos ha permitido conocer todas sus características, ya que por el perfil de las bocas y la forma de las bases era difícil su clasificación tipológica (Martínez Valle y Hortelano, 2012). El ánfora reconstruida SdP1205 es un modelo de cuerpo ovoide con una altura total en torno a los $73 \mathrm{~cm}$ y un diámetro máximo de $42 \mathrm{~cm}$; los hombros presentan una carena ligeramente redondeada, los labios están levantados, engrosados hacia el exterior, y forman un bisel hacia su parte interna. Las asas son gruesas, de sección circular y están colocadas directamente sobre la espalda y a la altura de la carena. El ánfora de las Pilillas es un modelo muy similar a los procedentes de Coll del Moro en Tivissa (Tarragona) o de Ampurias y otros que nos remiten a yacimientos del s. VI a.C. (Miró, 1989, 25) (Fig. 11). En el País Valenciano, las producciones locales más antiguas que imitan este tipo anfórico se documentaron en L'Alt de Benimaquia (Castelló et alii, 2000); presentan una altura de 46 a $56 \mathrm{~cm}$ y aparecen asociadas a viviendas que poseían lagares de tierra enlucidos con arcilla para producción de vino (Gómez Bellard y Guerin, 1995).

Otro modelo más evolucionado y con el perfil prácticamente completo es el ánfora SdP00894. Se trata de un modelo de cuerpo más alargado y hombros más redondeados con una altura conservada de $75,5 \mathrm{~cm}$ y estimada de no más de $80 \mathrm{~cm}$. El espesor mínimo es de $0,4 \mathrm{~cm}$ y el espesor máximo de $1 \mathrm{~cm}$, en las paredes del tercio superior. Las asas colocadas directamente sobre la espalda son gruesas, de sección circular y presentan una acanaladura longitudinal. El diámetro de la boca es de $12 \mathrm{~cm}$ y el borde está levantado y engrosado hacia el exterior con un bisel hacia el interior y con la parte superior aplanada. La pasta es alternante, con el exterior en tono ocre claro, casi amarillo, el núcleo gris y el interior rojizo. Este recipiente presenta la particularidad de que casi todo su interior está «craquelado», en muy mal estado, y se desescama con facilidad, especialmente en la base lo que ha hecho imposible su reconstrucción a pesar de estar completa. Da la sensación que el interior del ánfora estuvo en contacto con un acido que dañó toda la parte de la base; los análisis de la pasta degradada permitirán afirmar si el contenido del ánfora fue vino. Este tipo de ánforas, de formas más alargadas que la R1, 


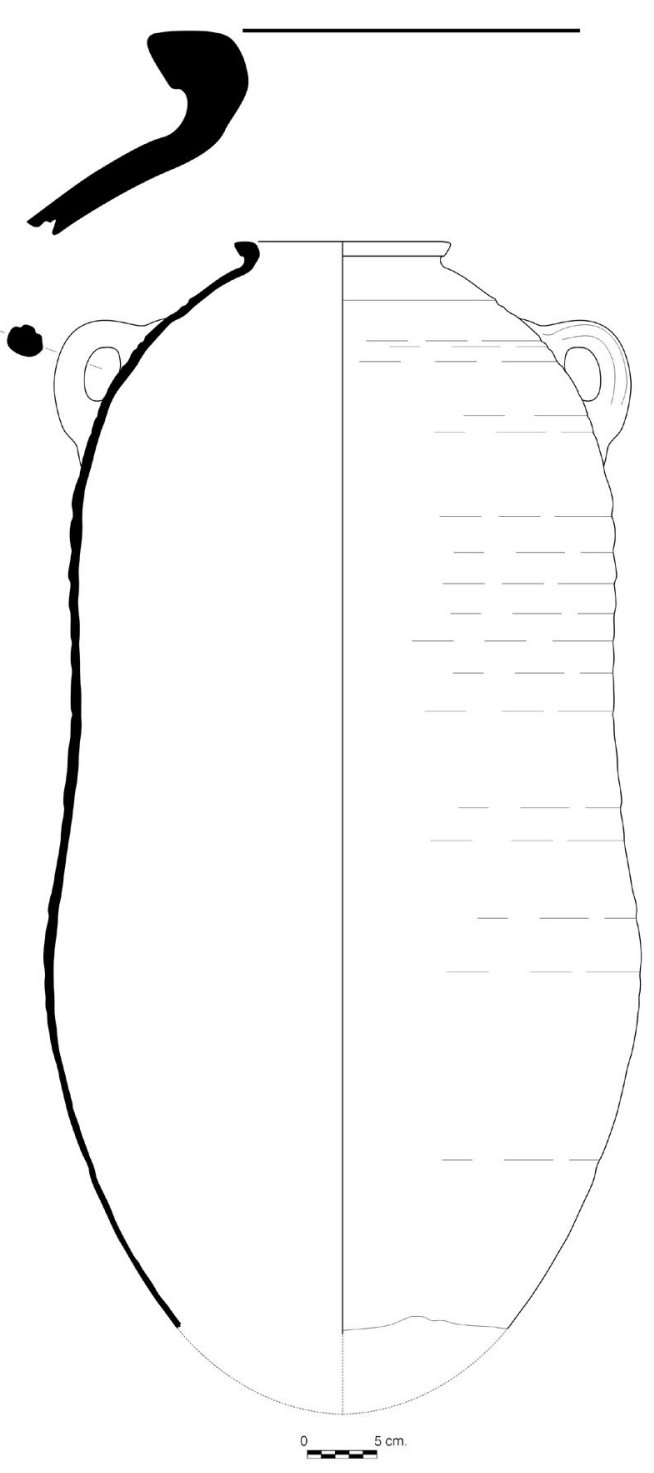

Figura 12: Ánfora de las Pilillas (SdP 0894).

se documentan también ampliamente desde finales del siglo VI a.C. (Ribera y Tsantini, 2008, 620) y hasta aproximadamente el tercer cuarto del s. V y se corresponderían con el tipo PE-11 de Ramón (Ramón, 1991, 103) y el A-2 de Muñoz para Andalucía (Muñoz, 1985, 471) (Fig. 12); el ánfora de la Solana de las Pilillas SdP00894 se aproxima bastante a algunos ejemplares de Ampurias (Gerona) y también del El Oral (Alicante) (Abad et alii, 1993, 206-207) y algunos modelos bien presentes en Ibiza (Ramón, 1991,102).

Junto a las ánforas documentadas para el proceso de vinificación, otras formas como barriletes, caliciformes, morteros o cerámicas de cocina, que permitían el contacto directo con el fuego, nos aproximan a la vajilla cotidiana y a las cerámicas más utilizadas en el proceso de elaboración. Estas cerámicas proceden en un buen porcentaje de las Casillas del Cura, donde se fabricaban ánforas y otras cerámicas relacionadas con el procesado del vino (Martínez Valle y Hortelano, 2013, 229-235) (Figs. 13 y 14). En la campaña de 2012, también se han documentado fragmentos de ánforas de importación fenicia, cerámicas bruñidas del Hierro Antiguo y recipientes a mano de bases planas, lo que serían indicios de ocupación de la Solana de las Pilillas a finales del s. VII a.C (Fig. 15).

Los valores culturales y la originalidad del conjunto de Las Pilillas han permitido su declaración como Bien de Interés Cultural ${ }^{6}$. Junto con el trabajo de excavación, y para delimitar el entorno del BIC del yacimiento, se inició la prospección sistemática de las ramblas de Los Morenos y de La Alcantarilla en búsqueda de nuevos lagares y para detectar el poblamiento que pudiera estar relacionado con este lugar de producción. Resultado de la prospección fue la localización de una nueva estructura frente a Las Pilillas, al otro lado de la rambla de Los Morenos, la pililla del Salto, un nuevo lagar que por la proximidad podría haber formado parte de este mismo complejo y que la erosión de la rambla ha hecho inaccesible desde el yacimiento (Ruiz Pérez, 2012, 47).

Por lo que respecta a la rambla de La Alcantarilla, se conocían hasta la actualidad un total de 6 estructuras concentradas en tres puntos diferentes, una en el Rincón de los Herreros, conocida como la pililla del Moro Eusebio, una en la Solana de las Carbonerillas, tres en la Rambla de la Alcantarilla y una pequeña almazara en la Solana de Cantos (Argilés y Sáez, 2008, 39). En verano de 2005, bajo la dirección de Consuelo Mata, se realizó una excavación junto a uno de los lagares de la rambla de La Alcantarilla; próximo al lagar se documentó un edificio de $150 \mathrm{~m}^{2}$ de superficie construida y unos $100 \mathrm{~m}^{2}$ útiles, con dos fases de ocupación entre los siglos V-III a.C. Sus excavadores, en base al tamaño y la mala calidad de la construcción, el espacio techado y sus ajuares básicos, interpretaron el edificio como un caserío y bodega que serviría para albergar, de manera estacional, a los trabajadores durante las épocas de vendimia así como para depositar las ánforas donde realizar la primera fermentación del vino (Quixal et alii, 2012, 64).

En las prospecciones realizadas para la declaración de BIC hemos detectado dos nuevos lagares próximos a la rambla de La Alcantarilla semiocultos entre la vegetación, y en ambos casos fracturados. Hasta la actualidad se conocen 14 estructuras excavadas en roca entre estas dos ramblas, pero falta por definir, en la mayor parte de casos, la cronología concreta de cada una de ellas y su relación con los yacimientos del entorno pero es interesante destacar la gran producción de vino detectada y en menor medida de aceite. Técnicos del Parque Natural de las Hoces del Cabriel nos comunicaron la existencia

6. El yacimiento arqueológico de La Solana de las Pilillas (Requena) es uno de los centros productores de vino más antiguos documentados en la Península Ibérica. Debido a su excepcionalidad se inició la incoación de Bien de Interés Cultural en la categoría de Zona Arqueológica. Resolución de 25 de noviembre de 2011, de la Consellería de Turismo, Cultura y Deporte y BOE n ${ }^{\circ} 270$ de 9 de noviembre de 2012, Sec. III pág. 78460. 


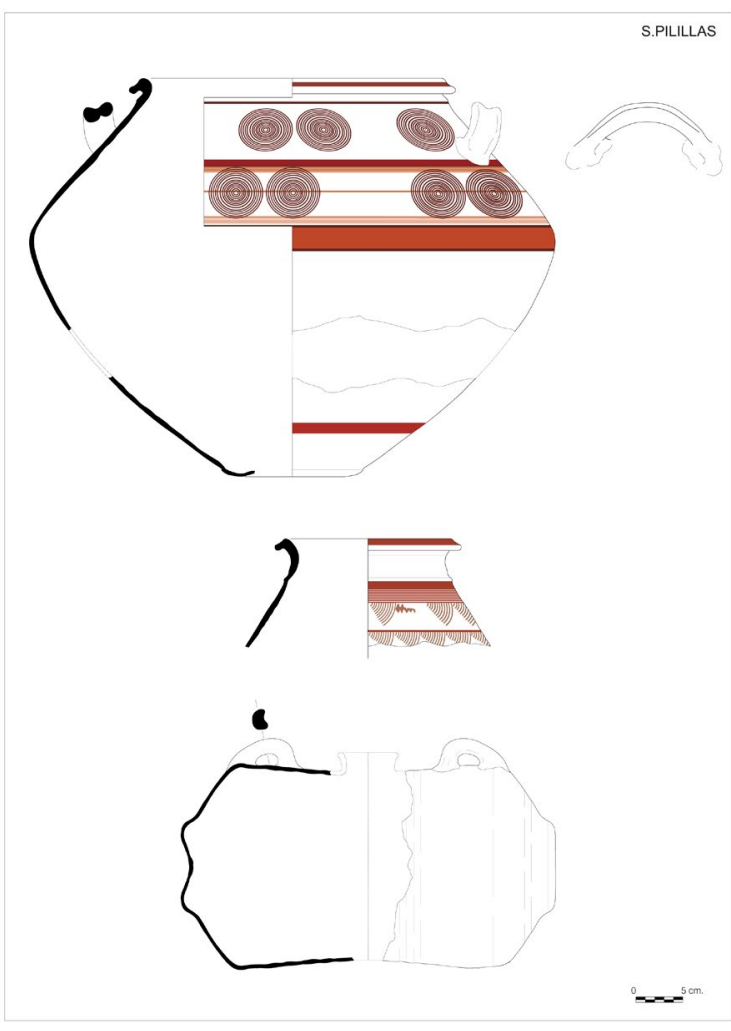

Figura 13: Cerámicas procedentes de las Pilillas asociadas a la elaboración y consumo de vino. Tinaja bitroncocónica; tinajilla y barrilete.

de dos lagares más junto a la pedanía de Casas del Río de Requena por lo que serían 16 estructuras excavadas en piedra en el entorno del río Cabriel.

En la rambla de La Alcantarilla, por la localización de los lagares y almazaras y los yacimientos conocidos del entorno se podría intuir que el sistema de ocupación respondería a un poblamiento disperso que utilizaría estas estructuras tras la cosecha para el procesado de la uva y la aceituna. Tanto los lagares como las almazaras aparecen aislados y no existen indicios de edificaciones asociadas, ni se aprecia material arqueológico que permita una datación concreta. En general las capacidades son reducidas y solamente el lagar del Rincón de los Herreros podría contener un volumen de mosto superior a los 2.000 litros; poco se puede aportar sobre su cronología y contexto, pero por su capacidad debió de estar asociado a una bodega próxima donde se realizaría la fermentación.

En cuanto a la bodega de Las Pilillas, tanto por la cronología de los materiales recuperados en la excavación como por la configuración del complejo pensamos que se correspondería con un modelo diferente del observado en la rambla de La Alcantarilla. Se trataría de una «bodega torre» o de un asentamiento dedicado a la producción de vino asociado a estructuras en apariencia defensivas y que podrían responder a un modelo similar al documentado en Aldobesta (Mascort et alii, 1991) y otros almacenes agrícolas del Matarraña (Moret, 2002,
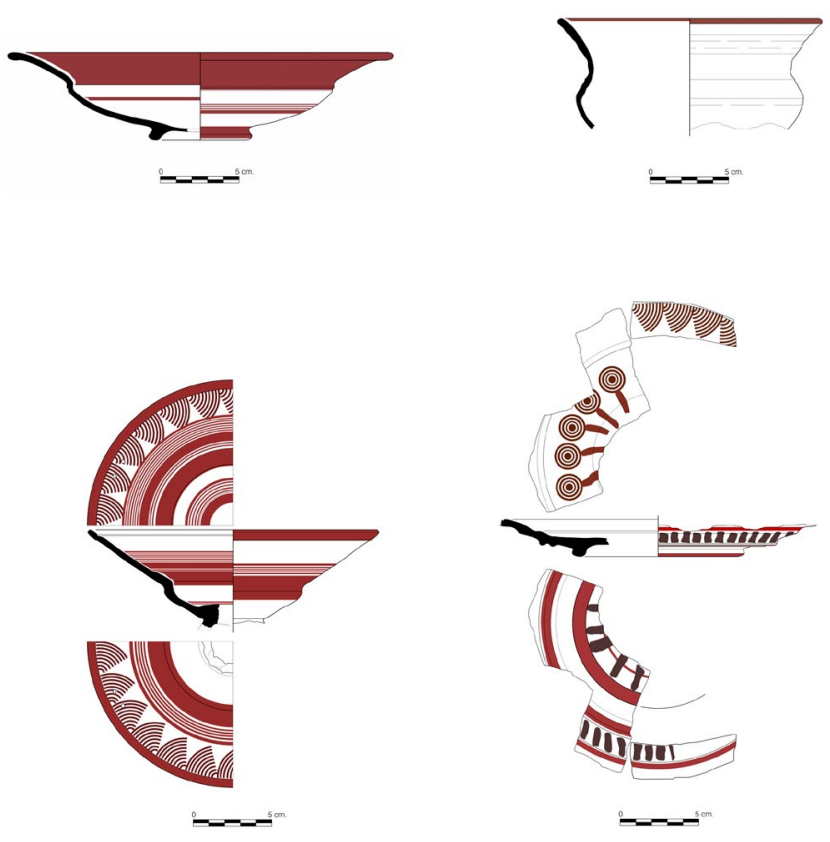

Figura 14: Platos y caliciforme.
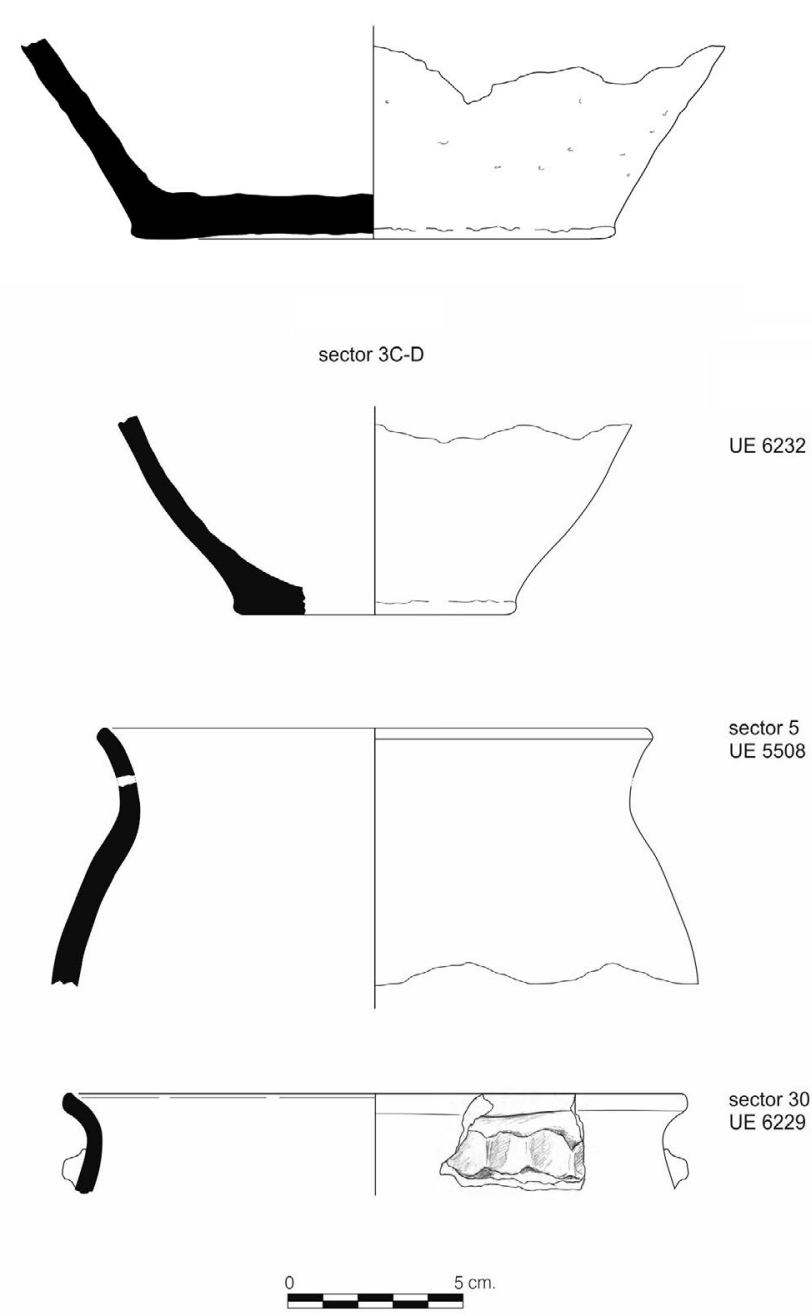

Figura 15: Cerámicas del Hierro Antiguo. 


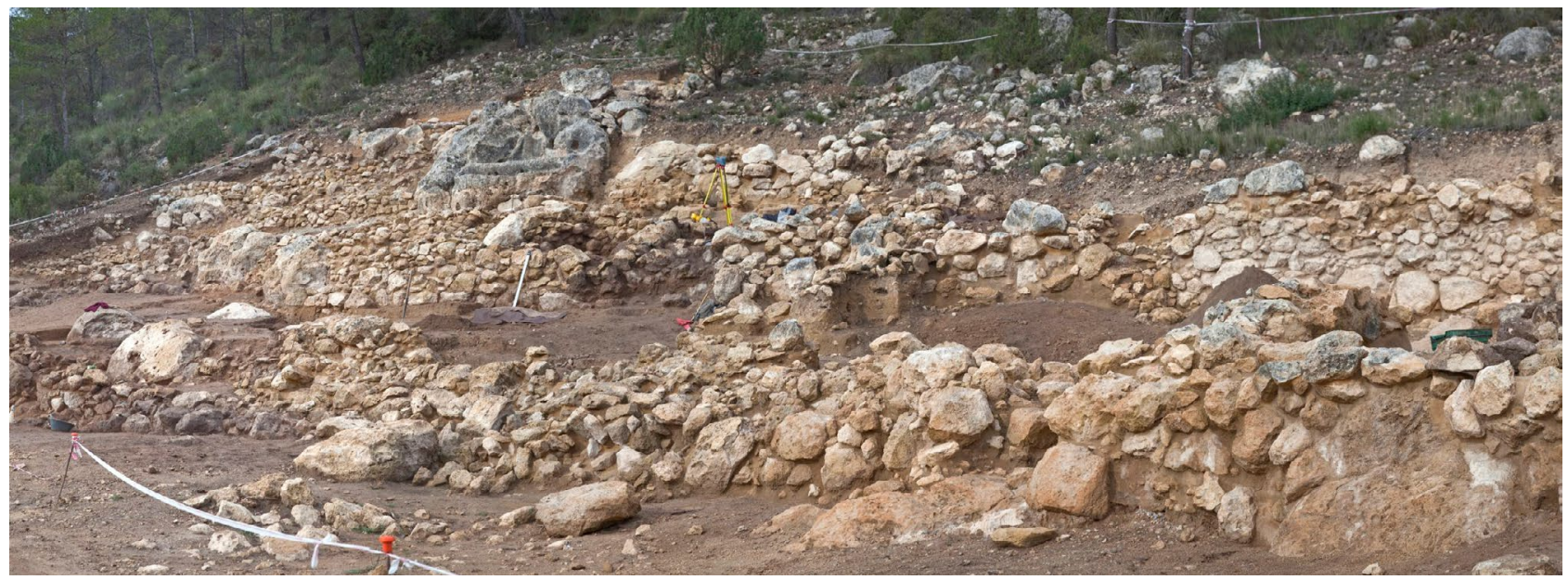

Figura 16: Fotografía del Sector Norte de la excavación.

65). En Las Pilillas el edificio torre de planta semicircular se adosa a la bodega y presenta una comunicación directa con el lagar. De momento falta por excavar el sector norte de la estructura pero se identifica bien su planta circular, con muros semicirculares que por la gran acumulación de tapiales deshechos estaría construido con zócalos de piedra y tapial, y que en el muro exterior alcanzaría los $3 \mathrm{~m}$ de anchura consiguiendo la apariencia de una torre junto al camino. Tanto los muros de la bodega, como los que configuran la «semi torre» podrían tener esas dimensiones para intentar mantener una temperatura constante que evitara que se estropease el vino, a parte de dar un aspecto de solidez al conjunto que reforzará la posición social de sus propietarios. El entorno de los otros lagares del complejo de Las Pilillas está por excavar pero por las alineaciones de muros que se aprecian en superficie podríamos decir que todo el complejo funcionó de forma unitaria desde finales del s. VII a finales del V a.C. (Fig. 16).

\section{LA PRODUCCIÓN DE ÁNFORAS EN CASI- LLAS DEL CURA}

La elaboración de contenedores cerámicos para la fermentación y el almacenaje son otro tipo de testimonio que se vincula con la producción de vino. El yacimiento de las Casillas del Cura documenta bien la elaboración de ánforas y de otras cerámicas relacionadas con la producción y el consumo del vino desde el s. VI a.C.

El alfar ibérico de las Casillas del Cura se sitúa en las estribaciones de la Sierra del Rubial (Venta del Moro, Valencia), a una altitud aproximada de $900 \mathrm{~m} \mathrm{~s}$. n. m., en un emplazamiento elegido por los alfareros por la proximidad a los principales lugares de aprovisionamiento de materia prima, básicamente, agua, arcilla y combustible. El yacimiento se sitúa junto a la Vereda Real, una vía de comunicación utilizada ya en época ibérica que permitiría la comunicación y el comercio con otros enclaves ibéricos de la comarca y del otro lado del Cabriel, a través de los vados y pasos de este río (Martínez Valle et alii, 2001, 148).

En el año 1996 se produjo un desfonde en el yacimiento para un cambio de variedad de viñedo; parte de los hornos quedaron destruidos y los testares volteados, quedando en superficie multitud de formas cerámicas. Una excavación de urgencia, promovida por el Ayuntamiento de Requena permitió intervenir en uno de los hornos del complejo y también realizar un sondeo en uno de los testares. Los restos del horno intervenido desaparecieron prácticamente hasta la parrilla si bien todavía pudimos documentar la planta completa, algunas de las toberas in situ y parte del alzado del laboratorio (Martínez Valle y Castellano Castillo, 1997, 61-69).

Por debajo de los restos fracturados de la parrilla y en el interior de las cámaras de fuego, se recuperaron más de 3.500 trozos de ánforas amontonadas como desechos de cocción. El hecho de que solo se documentaran ánforas, y en un depósito cerrado, nos hizo suponer que podría tratarse de formas completas fracturadas, por lo que decidimos iniciar su proceso de reconstrucción ${ }^{7}$. Con los perfiles completos de las piezas ya podemos conocer todas sus características y afirmar que las ánforas elaboradas en Casillas del Cura son también una derivación de las formas fenicias (Fig. 17).

Hemos diferenciado, a pesar de que hay muchos fragmentos inconexos, por el número de bordes al menos, quince ánforas diferentes. En general se puede decir que todas presentan características muy similares e importantes defectos de fabricación, fracturas en «S», producidas por acción del calor, deformaciones por exceso de agua, burbujas de aire en el interior de la pasta

7. Por medio de un convenio firmado con el Departamento de Conservación y Restauración de Bienes Culturales de la Universidad Politécnica de Valencia y durante siete campañas de verano de un mes de duración, alumnos de la especialidad de Restauración Cerámica han ido uniendo y reconstruyendo las ánforas hasta conseguir cinco formas completas y varias más bastante definidas. 

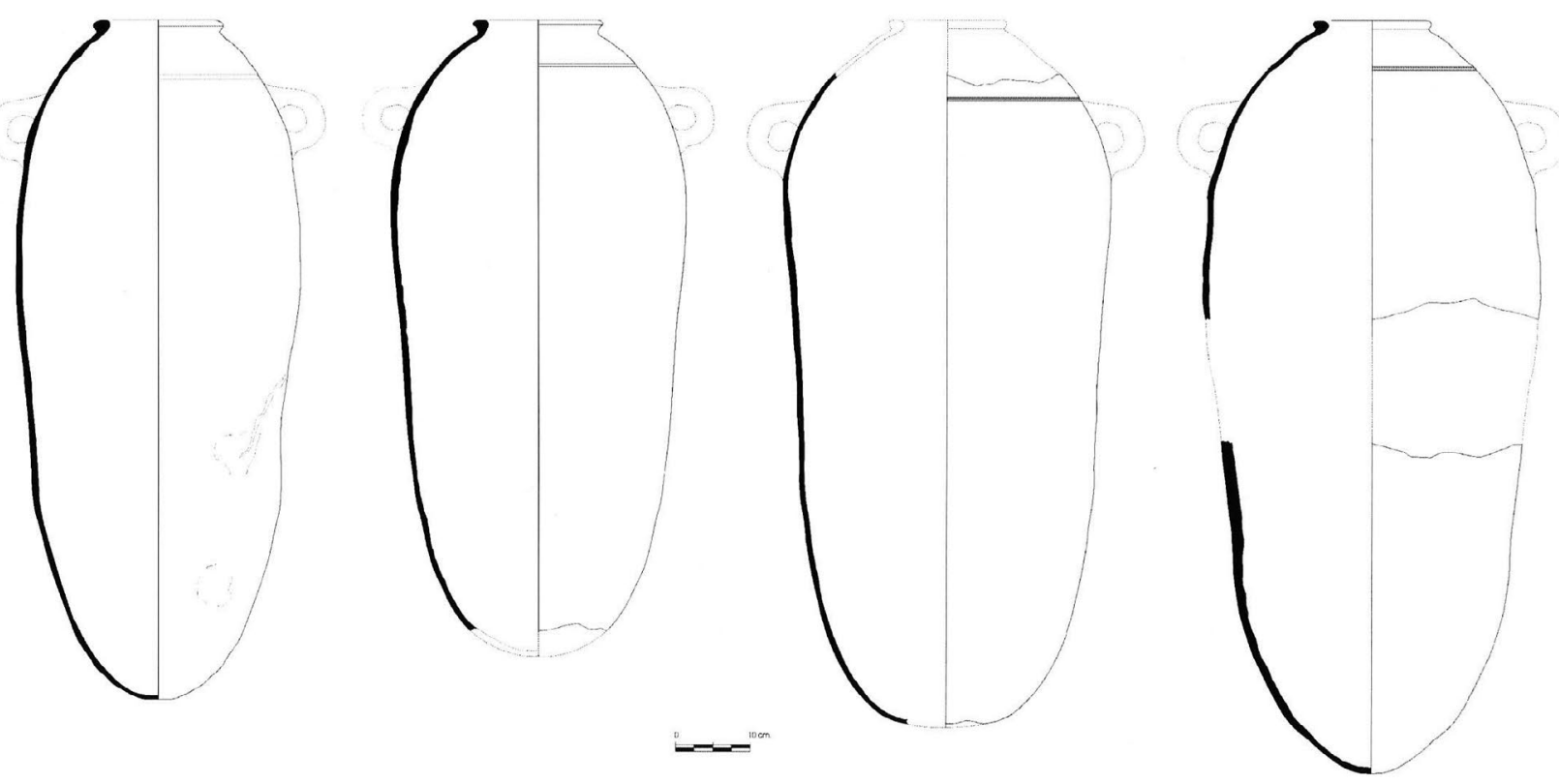

Figura 17: Perfiles de ánforas recuperados en el interior del horno de Casillas del Cura.
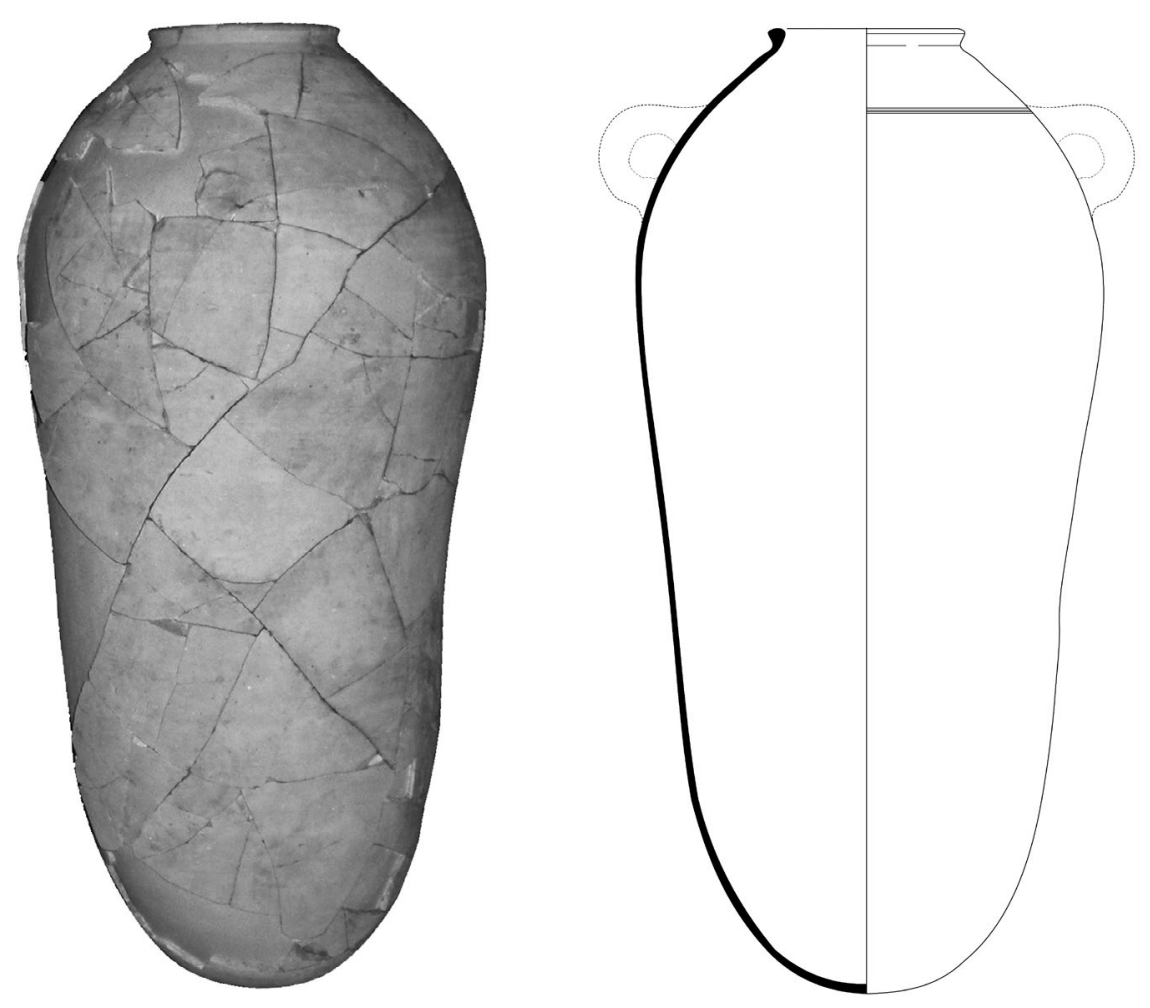

Figura 18: Ánfora de Casillas del Cura. Fotografía y dibujo.

y en general imperfecciones que nos hacen suponer que una vez el horno quedó amortizado se utilizó para recibir estas ánforas que debido a su mal estado no se pudieron comercializar. Todas las piezas que hemos reconstruido presentan características muy similares; se trata en general, de un modelo de cuerpo alargado, con una altura total en torno a los $83-85 \mathrm{~cm}$, con los hombros redondeados y con el diámetro máximo en el tercio superior, normalmente justo debajo de las asas, llegando a los $42 \mathrm{~cm}$. Las asas son gruesas, de sección circular, colocadas directamente sobre la espalda, son más altas que anchas y están poco elaboradas; estas ánforas, ligeramente estranguladas por su parte central, presentan un aspecto como de bellota (Fig. 18). 
Las pastas son homogéneas, de color anaranjado, muy depuradas, compactas y sin desgrasante visible. La cocción es oxidante, bien controlada y las superficies exteriores presentan un suave alisado. En el interior de las ánforas, son perfectamente visibles los surcos del torno, bien marcados y regularmente distribuidos. El espesor mínimo de las paredes, 0,5 $\mathrm{cm}$, suele darse en la base y a veces en el hombro; el espesor máximo, que puede alcanzar $1,5 \mathrm{~cm}$, suele estar en las paredes del tercio superior del galbo. Los diámetros interiores de la boca oscilan entre los 9 y $\operatorname{los} 14 \mathrm{~cm}$; la altura del labio entre 1,5 y $2 \mathrm{~cm}$ y el ancho puede llegar a los $2 \mathrm{~cm}$. Los labios están levantados y engrosados hacia el exterior y hacia el interior, formando un bisel en la cara interna más o menos pronunciado, lo que ha dado lugar a su agrupación en 3 subtipos:

Labio subtriangular, si el bisel se inicia en el borde externo del recipiente. Responden a este perfil el $42 \%$ de los bordes inventariados de todo el conjunto.

Labio aplanado, si el bisel viene precedido de una superficie aplanada. Sucede en un $24 \%$ de los bordes.

Labio redondeado, si la sección sube ligeramente desde la parte exterior y baja con suavidad, como se observa en el $25 \%$ de los bordes recuperados.

Por el momento no hemos documentado claros paralelos para las producciones de Casillas del Cura; no obstante podemos relacionar estas formas con los tipos B3 y C2 del Cerro Macareno (Sevilla) (Ruiz y Molinos, 1993, 64). La base redondeada y las asas sobre la espalda de la B3, propias de las formas más arcaicas, se combinan en el caso de las Casillas del Cura con una estilización del tercio inferior del tipo $\mathrm{C} 2$, pudiendo situarse entre ambos tipos, con una cronología de la primera mitad del s. V. a.C.

Respecto a la tipología de las ánforas del Mediterráneo Occidental de Ramón (1995), ninguno de los tipos presentados por este autor coincide con las características de las producciones de Casillas del Cura. El tipo más similar podría ser la forma 1.4.3.1., documentada en la primera mitad del s. V a.C., con un cuerpo alargado y tendente hacia las formas cilíndricas de la $2^{\mathrm{a}}$ mitad de este siglo. El único ejemplar que conocemos similar a este tipo anfórico se recuperó en el área púnica del Mediterráneo Central, en Mozia (Sicilia) en las proximidades de Marsala, un ánfora de $75 \mathrm{~cm}$ procedente del mar y sin contexto arqueológico (Ramón, 1995, 175).

Otros recipientes elaborados en Casillas del Cura se relacionan con la producción y consumo del vino. Entre estas formas podemos incluir caliciformes, morteros, tinajas con pico vertedor, barriletes y soportes perforados para sustentar las ánforas; exceptuando los soportes perforados, todas estas formas las hemos documentado en la Solana de las Pilillas (Martínez y Hortelano, 2013, 235).

\section{OTROS TESTIMONIOS DE VITICULTURA EN ÉPOCA IBÉRICA}

La producción de vino en la Meseta de Requena Utiel ha quedado atestiguada también en el Molón de Camporrobles durante el Ibérico Pleno, un poblado situado en las estribaciones de la Sierra de Aliaguilla, en uno de los límites geográficos de la Meseta de Requena Utiel. El Molón tuvo una ocupación continuada desde inicios del Hierro Antiguo hasta el s. I a.C., y también tiene ánforas R.1, que documentan un temprano consumo. En el s. IV a.C., en una vivienda del Sector Oriental del poblado, en el departamento $\mathrm{C} 1$, se excavó una plataforma inclinada construida con piedras de pequeño y mediano tamaño que comunicaban por medio de un canal con una cubeta de 0,67 por $0,48 \mathrm{~m}$ y 0,30 de profundidad, configurando un lagar, que podría recoger unos 97 litros de mosto, que se trasegarían a los contenedores cerámicos para su fermentación (Lorrio et alii, 2009; Lorrio y Sánchez del Prado, 2013, 163); un testimonio de producción de vino que encuentra sus paralelos en poblados de la misma cronología como El Tossal de Sant Miquel de Llíria, y la Monravana, también en territorio de Edeta (Bonet, 1995, 108). Tanto en San Miquel como en el Molón, las semejanzas estructurales de los lagares y las características de las viviendas podrían relacionarse con un espacio de actividades económicas vinculado a las elites de ambos poblados. En Alicante, en El Campello, también se han documentado lagares de esta cronología (Olcina, 2005, 154-156).

En Kelin (Caudete de las Fuentes), hasta la actualidad, no se conocen lagares para la producción de vino, pero sí hay testimonios de un temprano consumo y lo que podría ser la casa de un comerciante de vino del s. III a.C. En este poblado, es donde más testimonios de cerámicas de importación relacionadas con el vino se han documentado sobre todo kylikes y skyphoi y algunas imitaciones de copas que se utilizarían en banquetes, funerales o celebraciones especiales.

En la campaña de 1979 se recuperó una copa jonia tipo B2 que permitió datar las cerámicas indígenas de su contexto en el s. VI a.C. (Pla, 1980; Mata, 1991). Posteriormente, en una vivienda de esta misma cronología se documentó un ánfora ibérica hincada en el suelo que por la analítica realizada pudo haber contenido vino (Tresseras y Matamala, 2004, 286); su forma recuerda a la Serie 10 de Ramón $(1995,229)$, pero con características técnicas diferentes por lo que ya, en el momento de su excavación, se apuntó la posibilidad de que este ánfora fuese de procedencia local. De este mismo nivel arqueológico, del siglo VI a.C., en otro sector del yacimiento se recuperaron otros seis ejemplares que también se consideró podrían ser producciones locales (Mata, 2006, 127). La elaboración de vino en la Solana de las Pilillas podría explicar la presencia de estas ánforas en niveles del s. VI a.C. en la ciudad de Kelin. 


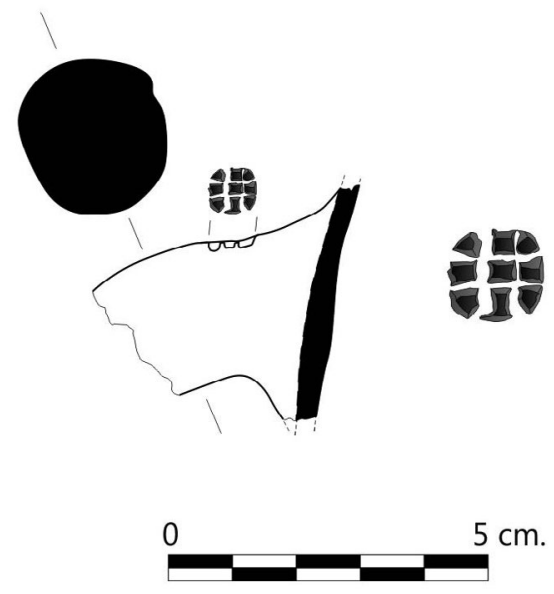

Figura 19: Marca sobre el asa de un ánfora de Casillas de Cura.

En relación con el comercio y la producción de vino debemos enmarcar las estampillas impresas sobre asas de ánforas y citar el reciente trabajo de David Quixal y otros colaboradores (Quixal et alii, 2012, 66) donde se recogen varios testimonios repartidos en distintos yacimientos comarcales de un mismo modelo de estampilla impresa. El lugar donde más ánforas marcadas se documenta es en Kelin y La Atalaya de Caudete de las Fuentes pero también en Moluengo (Villargordo del Cabriel), yacimiento muy próximo a Casillas del Cura que pudo servir de centro de distribución de los productos de este alfar (Martínez Valle et alii, 2001, 146); en la rambla de La Alcantarilla también se ha recuperado un testimonio, destacable por ser un yacimiento asociado a la producción de vino. Referente a estas marcas aportamos un ejemplar del mismo modelo recuperado en Casillas del Cura (Fig. 19). Hasta la actualidad este yacimiento es el único alfar en la comarca que documenta producción de ánforas en el Ibérico Antiguo por lo que la localización de dos asas de piezas distintas con la misma marca impresa, asociadas a uno de los testares, nos permite afirmar su procedencia y su vinculación con la distribución y el comercio del vino; otras estampillas diferentes sobre asas de ánfora recuperadas también en Casillas del Cura, apuntarían a que estas marcas, más que identificar el lugar de producción, identificarían contenidos o propietarios (Mata et alii, 1997) que encargarían sus recipientes cerámicos con marcas propias como un sello personal.

De finales del s. III a.C. es el conjunto de 70 ánforas y una gran concentración de pepitas de uva carbonizadas en la estancia principal de una vivienda de Kelin; sus excavadores interpretaron que podría ser la casa de un comerciante de vino (Mata et alii, 1997), si bien los análisis realizados en las cerámicas no han permitido afirmar la existencia de vino en el interior de las ánforas. De este mismo yacimiento es la copa para beber vino que presentamos y que está decorada con una representación naval.

\section{IMITACIÓN IBÉRICA DE UNA COPA GRIEGA CON REPRESENTACIÓN NAVAL}

La copa que presentamos procede de un hallazgo casual consecuencia del desfonde de un campo de vides localizado en una zona marginal de Kelin y fuera del espacio protegido propiedad de la Diputación de Valencia ${ }^{8}$. La copa según hemos podido saber se recuperó fracturada y no se encontró el pie, teniendo de esta manera una apariencia desproporcionada y achatada (Fig. 20). La forma de la copa nos recuerda a un cántaro ático pero la perdida de la base desdibuja su forma original, por otra parte las asas que parten del inicio de la panza cierran de forma horizontal a la misma altura y no sobrepasan el borde de la copa, como ocurre con los cántaros, siendo más propias de los kylikes (Page, 1984, 41). La pasta es de color marrón claro y está bien torneada, pero se aprecian algunos defectos que se produjeron en el proceso de elaboración, numerosas burbujas en toda la superficie que indicarían un exceso de humedad en el momento de realizar la cocción y que podrían ser consecuencia de que la pasta no adquirió la dureza cuero necesaria para evitar las deformaciones en el horno. El exceso de agua se aprecia también en la superficie de las asas que se ven aplanadas en su parte superior, como consecuencia de haberse apoyado por esta parte en el horno, antes de realizarse la cocción.

Documentar la imitación de una forma griega para el consumo de vino es interesante, pero por lo que destaca esta copa es por su decoración, dos barcos muy similares que difieren en pequeños detalles y en el color, uno en granate y el otro en negro, y de los que surgen sendas guirnaldas que los cubren en su totalidad. El borde de la copa, por su parte interna y externa, presenta dientes de lobo, más evidentes por el exterior, y las asas pequeños trazos y pinceladas sin forma definida. Analizando más detenidamente las embarcaciones se puede ver cómo en ambos casos el casco presenta líneas más o menos paralelas y oblicuas en toda su superficie y por encima de este una serie de semicírculos enlazados, que van de parte a parte del barco, son el origen de un enramado que con las puntas en espiral cubren toda la nave. Por debajo del casco, espirales similares a las pequeñas volutas de la parte superior nos remiten al oleaje del mar adquiriendo el dibujo, de esta manera, cierta simetría. En la embarcación de color vino se identifican más claramente la proa y la popa. En la de coloración más oscura la proa parece

8. La primera vez que se publicó esta copa fue en el año 2001, en el $\mathrm{n}^{\circ} 8$ de la portada de la Revista «Color Aroma y Sabor «que edita el Consejo Regulador de la Denominación de Origen Utiel-Requena; posteriormente, en el 2009, se volvió a utilizar la imagen de la copa para un díptico promocional del «Paisaje Cultura de la Vid y el Vino», junto a uno de los lagares rupestres de la rambla de La Alcantarilla. A partir de ahí indagamos sobre el paradero de la copa para poder realizar un estudio más detallado de su decoración. 

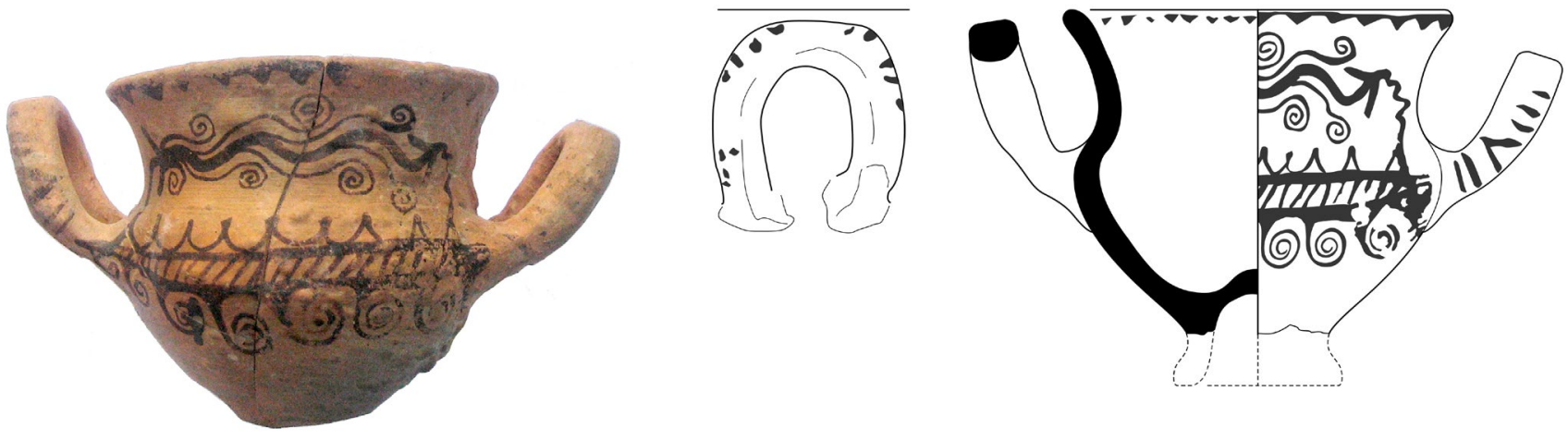

Figura 20: Copa ibérica con representación naval, Kelin (Caudete de las Fuentes, Valencia).

más corta y en el lugar de la popa destaca un objeto, por debajo de la parte inferior del casco, que por su situación podría ser un timón, si bien la forma se asemeja más a lo que podría ser un ancla lítica, aunque su situación lo contradice.

El motivo vegetal en los dos barcos es también muy parecido. En el origen de la guirnalda se aprecia lo que podría ser un tronco, de donde surge el enramado que termina en la popa. En la embarcación más rojiza la guirnalda termina en un trazo curvo de difícil interpretación; en la más oscura, en una punta de flecha de la
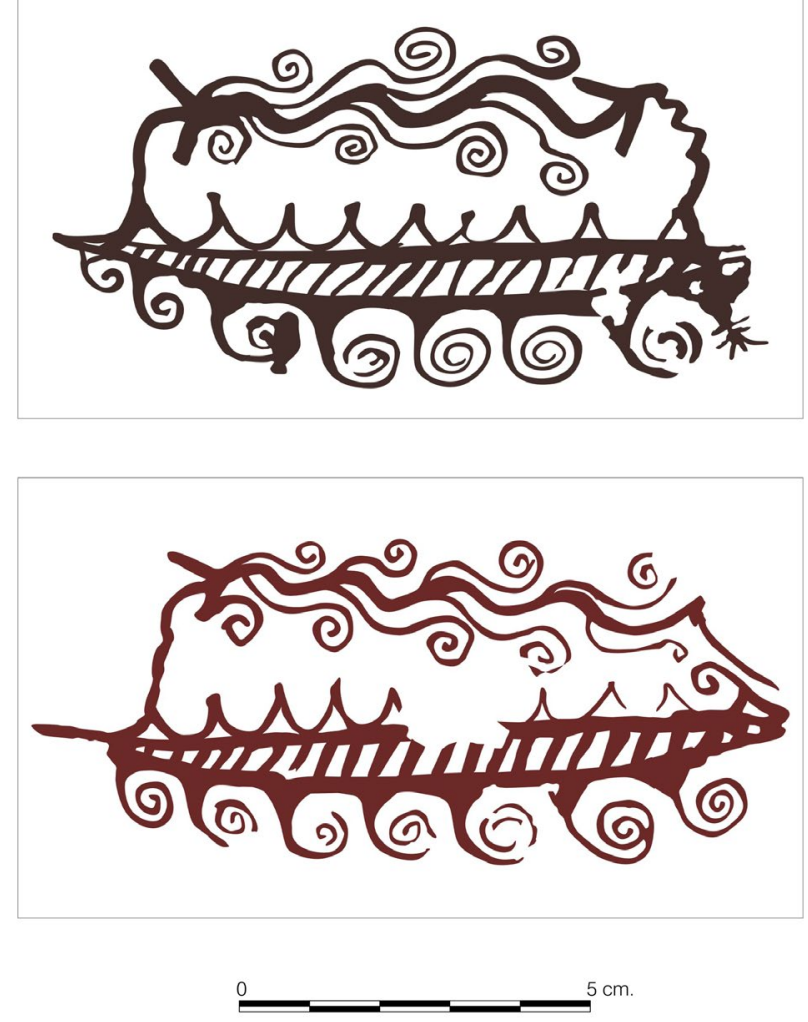

Figura 21: Decoración de la copa de Kelin. que nace una línea ondulada, como un brote tierno que permitiría que la planta se enredase y siguiera creciendo (Fig. 21).

Representaciones de embarcaciones en cerámicas ibéricas conocemos algunos ejemplos. En nuestro entorno más inmediato, procedente del Cerro de San Cristóbal (Sinarcas), las tenemos sobre una cajita de cerámica con decoración incisa. Los dos barcos representados son monóxilos con una vela, en los que se aprecian pocos detalles y que tienen poco que ver con el modelo que presentamos, simplemente señalar las líneas paralelas y oblicuas que se ven en el casco, en uno de los casos, y que se podrían relacionar con remos muy esquemáticamente representados (Martínez García, 1986).

Procedentes del Tossal de S. Miquel de Llíria (Valencia), se conocen cuatro fragmentos de vasos que tienen alguna representación naval. El más completo es el vaso $\mathrm{n}^{\circ} 122$, reproducido en numerosas ocasiones y que se recuperó en un recinto cultual con un pozo que contenía un depósito votivo. En este lebes se aprecian dos embarcaciones monóxilas asimétricas y en una de ellas lo que podría ser la proa levantada, con una representación zoomorfa en el extremo, pero en ninguno de los casos encontramos semejanzas con las embarcaciones de la copa de Kelin. En el vaso $\mathrm{n}^{\circ} 222$, se ve un fragmento de la proa de un barco, en este caso una embarcación grande que podría contar con bodega y tratarse de una nave de carga, pero también se aleja del modelo de nuestra representación. Los otros dos fragmentos por su reducido tamaño nos aportan poca información (Pérez Ballester, 2002, 286).

Del Puntal dels Llops (Olocau, Valencia) procede un fragmento donde se identifica la proa de una embarcación con la parte superior de la roda rematada por una cabeza de animal. Lo que destacamos es la serie de líneas oblicuas y paralelas similares a las que se ven en la copa que presentamos y que permite pocas interpretaciones más allá de ser unos remos o un escalamote o barandilla. 
Sin duda la representación más completa y que permitiría apuntar alguna semejanza con la copa que presentamos, procede de Más Boscá (Girona) (Maluquer, 1965, 129-138); se trata de dos embarcaciones grafitadas sobre una jarrita con dos asas de tipo «gris ampuritano» antiguo. A pesar de su diseño esquemático, se reconoce en ambas embarcaciones el mástil central, con una verga que sustenta la vela desplegada, y los remos que en una de las embarcaciones aparecen en dos hileras, a cada lado del casco de la nave. La popa curvada, levantada y en la proa con timón lateral, nos aproximan a los modelos de embarcaciones griegas del los s. VI a IV a.C. pero que sin duda debió de ser un tipo de nave bastante común en el Mediterráneo durante esos siglos. Destacamos también en ambos casos el ojo profiláctico que suele aparecer en la proa en este tipo de embarcaciones (Fig. 22). En Ampurias, en la campaña de excavación de 1985 se recuperó un plomo enrollado, de la segunda mitad del s. VI a.C., con una inscripción en griego que documenta la navegación de cabotaje y el comercio de vino por parte de los emporitanos con la ciudad de Saigantha (Sagunto), siendo un valioso testimonio de navegación por las costas de esta parte del Mediterráneo (Santiago, 1990, 126). Los paralelos a nuestra representación los encontraríamos en estas galeras y pentecónteras que vemos representadas en los vasos de figuras negras, que reproducen escenas cotidianas o mitológicas griegas (Casson, 1994, figs. 35-37, 49; Pomey et alii, 1997, 72 y 79) y que de alguna manera marcaron un estereotipo de representación naval que se reflejaría en la forma de esquematizar los remos, escalamotes o el oleaje del mar.

En relación con la guirnalda, hemos buscado representaciones vegetales similares a las que presenta la copa, asociadas a la iconografía ibérica conocida (Badal et alii, 2010). Las guirnaldas con zarcillos y volutas espiraliformes se suelen asociar a la vid o a plantas trepadoras; las representaciones de vid en el mundo ibérico son escasas y en pocos casos se pueden identificar de una forma explícita, ya que se confunden con otras plantas trepadoras, debido al esquematismo que les caracteriza.

En cerámica conocemos un ejemplo que permite identificar claramente una planta de vid, el kalathos de belikiom de Piquete de la Atalaya (Azuara, Zaragoza), (Royo y Minguell, 1992; Domínguez, 1998, 154; Badal et alii, 2010, 27) en cuyo caso se representan completos los elementos que identifican esta planta: un sarmiento con sus hojas, los zarcillos y su fruto, los racimos de uva.

En un kalathos del Corral de Saus, (Moixent, Valencia) de finales del s. III a. C se aprecia en la parte superior del recipiente una guirnalda muy similar a la representada en esta copa; de un eje más grueso surgen ramificaciones finas que terminan en pequeñas espirales a modo de zarcillos, sin ningún otro elemento que permita una clara interpretación (Badal et alii, 2010, 128) (Fig. 23).
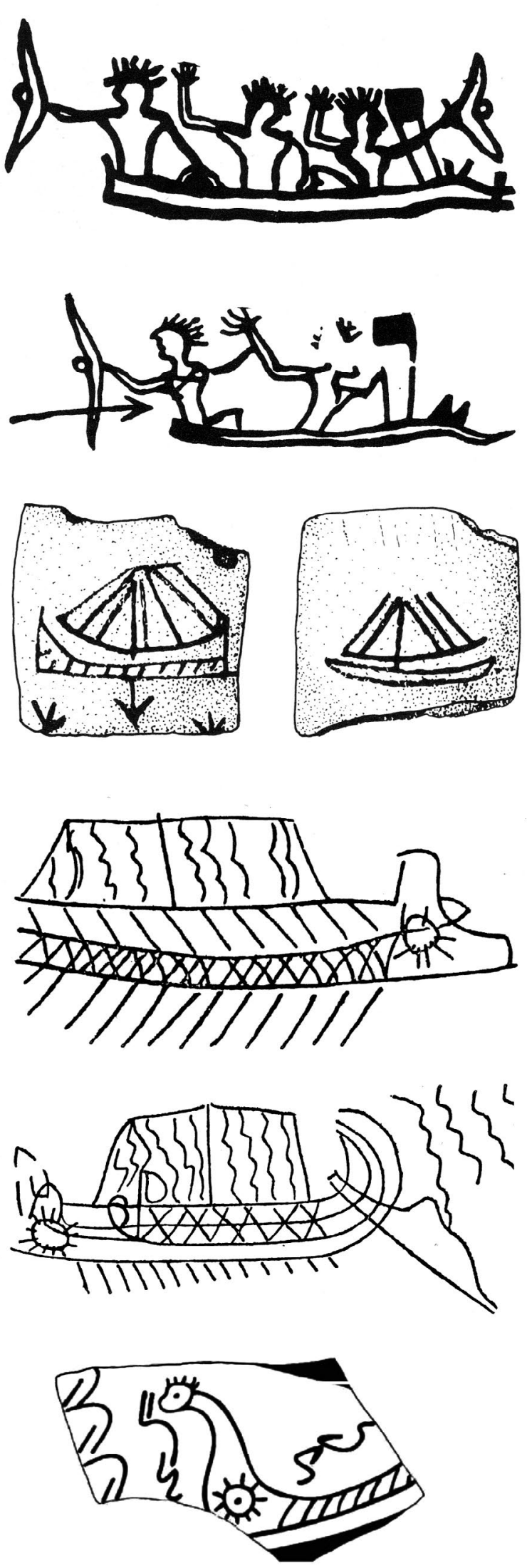

Figura 22: Representaciones de embarcaciones en época ibérica. De arriba abajo, Tossal de S. Miquel de Llíria (Valencia) $(1,2)$; Cerro de San Cristóbal (Sinarcas) $(3,4)$; Más Boscá (Girona) $(5,6)$ y Puntal dels Llops (Olocau, Valencia) (7) (Pérez Ballester, 2002). 

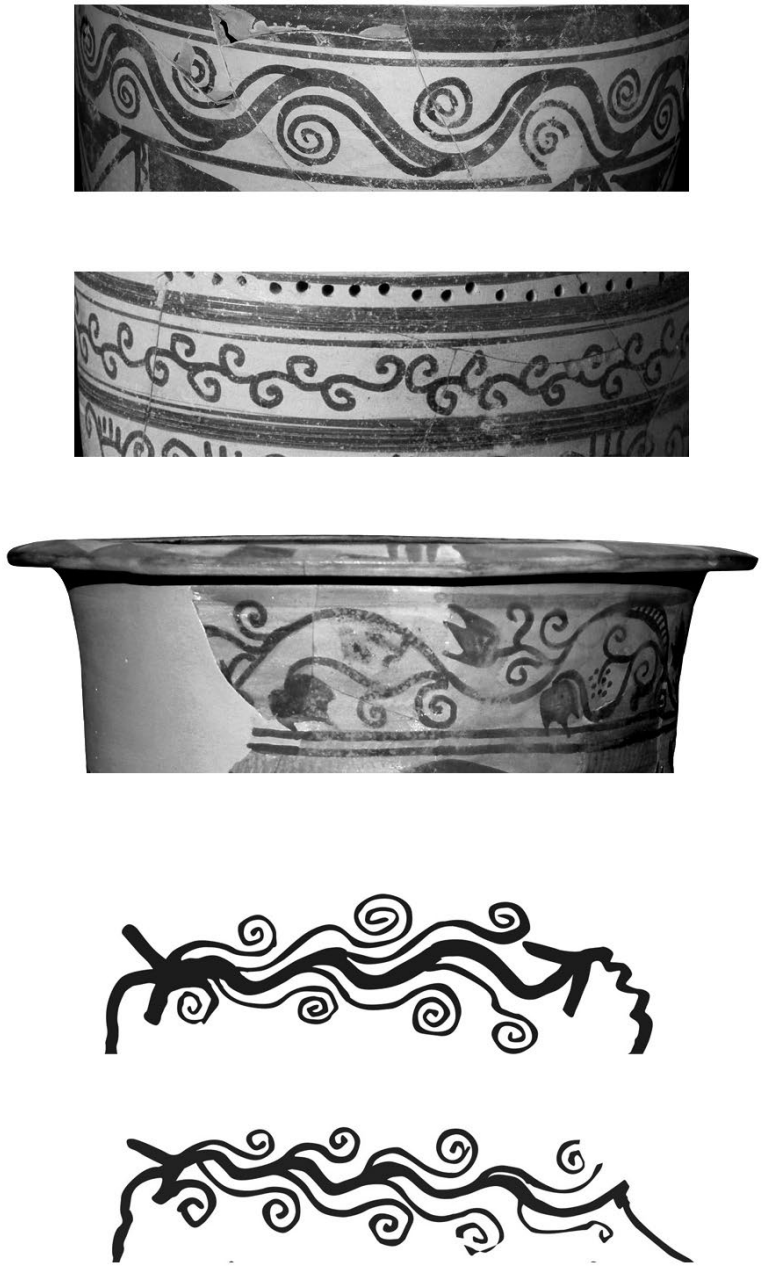

Figura 23: Representaciones de vid en cerámica ibérica. De arriba abajo, Corral de Saus, (Moixent, Valencia); La Escuera (San Fulgencio, Alicante); Piquete de la Atalaya (Azuara, Zaragoza) (Badal et alii, 2010); Caudete de las Fuentes (Valencia).

Buscando otros tipos de soportes, en las monedas, las representaciones de parras y uvas son más abundantes y aparecen en numerosos casos asociadas a ciudades productoras de vino. En un caso concreto en la Península Ibérica se representa una cepa completa en el reverso de una acuñación de Ulia, del s. II a. C. y se aprecia bien el tronco, de una manera similar al que puede verse en el inicio de la guirnalda de la copa de Kelin (Anson, 1976, part III, 442-473) (Fig. 24).

La interpretación que hacemos del motivo decorativo que vemos representado en la copa que presentamos, un barco cubierto por un emparrado y asociado a una copa de beber vino, nos permite relacionar esta imagen con el conocido mito del rapto de Dionysos por los piratas tirrenos. El Séptimo Himno de Homero relata cómo estando el joven Dionysos en la orilla del mar fue avistado por unos piratas que por su porte y belleza lo confundieron con el hijo de una persona rica o incluso de un rey. Los piratas lo apresaron con la intención de venderlo y conseguir un buen rescate, su actitud despreocupada no hizo sospechar a los raptores
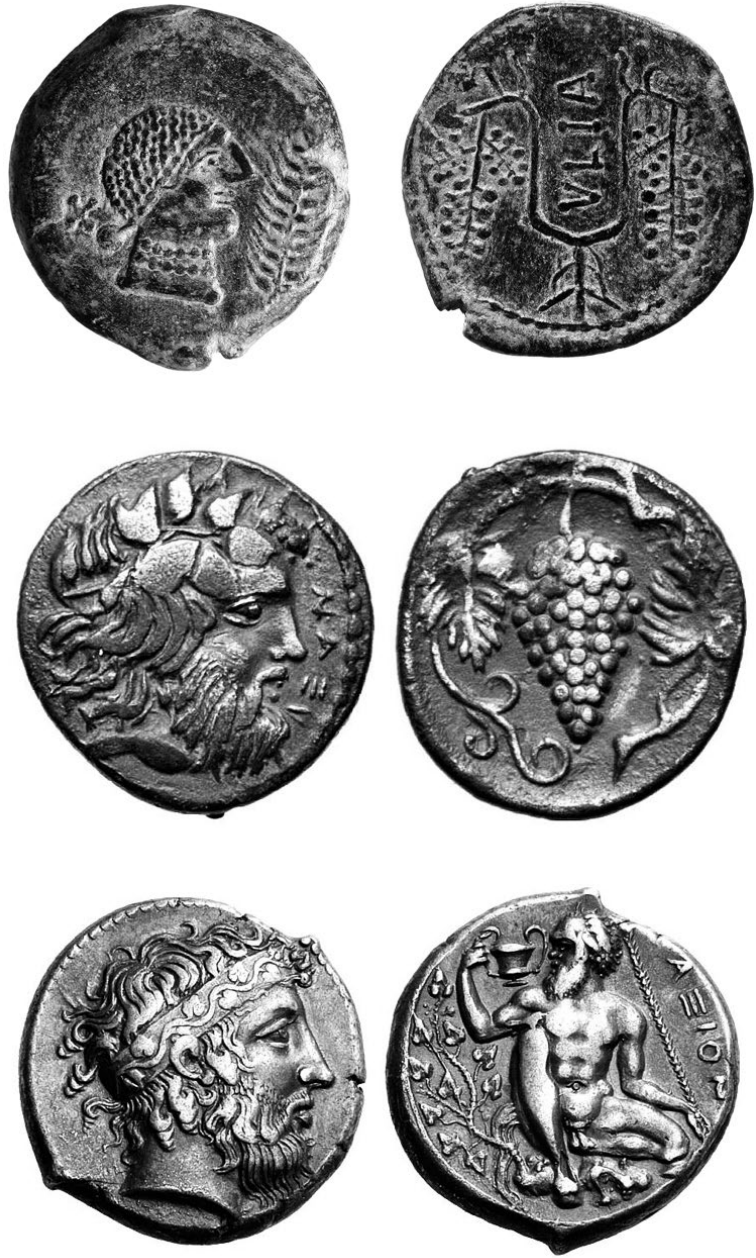

Figura 24: Representaciones de vides en monedas antiguas. De arriba abajo, unidad de Ulia, siglo II a.C. (col. privada); hemidracma de Naxos, 405-403 a.C. (Art Coins Roma 5/12/2011, lote 593); Tetradracma de Naxos, 430-420 a.C. (col. privada).

de su naturaleza divina y ya en el barco, cuando intentaron atarlo, las cuerdas se aflojaban y Dionysos sonreía despreocupado. Solamente el timonel comprendió que algo anormal ocurría y quiso evitar la tragedia intentando convencer al capitán para liberar al dios, pero el capitán ordenó navegar a toda vela rumbo a algún país lejano donde poder vender su captura.

Cuando iniciaron la travesía comenzaron a producirse diversos prodigios. Un perfume de vino dulce invadió el barco y manaban chorros de vino por todas partes. De la vela y la madera del barco comenzaron a brotar sarmientos de cepas y racimos que cubrieron toda la embarcación. Los piratas intentaron escapar y Dionysos convertido en un gran felino atrapó al capitán; la tripulación se arrojó al agua, pero Dionysos los transformó en delfines. Solamente el joven timonel fue recompensado por el dios y pasó a formar parte de su séquito divino.

El himno de Dionysos y los piratas tirrenos fue muy popular en la Antigüedad y aparece reflejado en varios textos clásicos (Torres, 2000, 651-6; 2005), con 

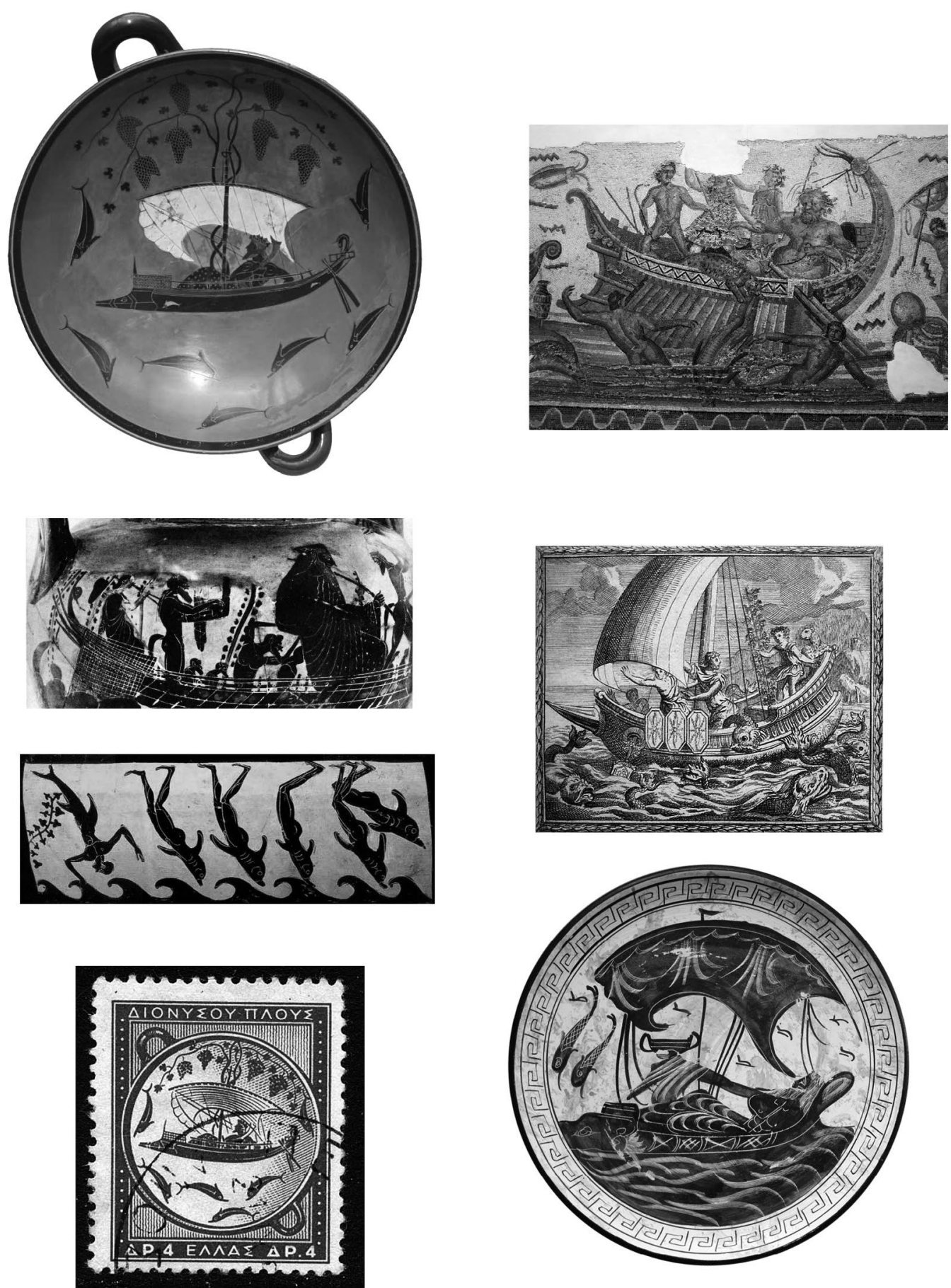

Figura 25: Representaciones del VII Himno a través de la historia. De arriba abajo, kylix de Exekias de 540 a.C., (Vulci Italia) (Staatliche Museen); ánfora de figuras negras, Tarquinia (Museo Nacional); ánfora figuras negras (Museo de Bellas Artes, Boston); mosaico de Dougha (Túnez) (Museo del Bardo); grabado del s. XVIII (Paris); sello de correos y souvenir actual de Atenas.

algunas variaciones, que no desvirtúan la versión original. Se conocen pocas representaciones, sobre cerámica que aludan a este mito pero sin duda, la más conocida es el kylix de Exekias de 540 a.C., recuperado en Vulci y que representa a Dyonisos recostado y bebiendo bajo el emparrado rodeado de los piratas ya convertidos en delfines.

De Tarquinia procede un ánfora de figuras negras que también interpreta este mito en las dos caras de la pieza. En una parte se ve a Dionysos con su cántaro bajo el emparrado acompañado de su corte de sátiros y bacantes; en la otra, los mismos personajes aparecen con un doble aulos y una citara o lira navegando plácidamente sin representar, en ningún caso, los piratas o los delfines.

En arquitectura, tenemos una alusión a Dionysos en el monumento conocido como la Linterna de Lisicrates del 335-34 a.C. Se trata de un monumento 
cilíndrico que representa un pequeño templo corintio que conmemora el premio recibido por un coro de hombres en el teatro de Dionysos (Atenas). En el friso, decorado con relieves, se representa la metamorfosis de los piratas que se relata en el VII Himno.

Relacionados con Roma, otros testimonios evidencian la aceptación de este mito como un plato recuperado en las excavaciones del Foro del s. IV a.C. (Pomey et alii, 1997, 47) o el mosaico del s. III d. C que procedente de Dougha (Túnez), reproduce el momento en que los piratas inician su transmutación con la parte superior del cuerpo todavía humana y el resto, introducido en el agua, ya como delfines. Tanto la copa de Vulci de Exequias como este mosaico que se conserva en el museo del Bardo, han sido reproducidos reiteradamente haciendo de este mito uno de los más conocidos desde la Antigüedad (Fig 25). Otros testimonios arqueológicos, menos explícitos, aluden a este mito como son las figuras de delfines o felinos sobre las anclas (Pomey et alii, 1997, 47) que adquieren un carácter profiláctico o de protección de la nave sobre un hecho bien documentado desde la antigüedad que es la piratería y el rapto de personas para pedir un rescate o venderlas como esclavos.

La copa que presentamos se suma a los testimonios mediterráneos de aceptación de este mito y presenta la peculiaridad de que tanto por los defectos de cocción como por la forma poco ortodoxa que presenta podría tratarse de una producción local interpretada por un artesano que poco sabría de embarcaciones griegas, pero que conocía bien la «cultura del vino», la relación con Dionysos y sus mitos, posiblemente a través de la tradición oral.

Hemos medido la capacidad de la copa en $\mathrm{cm}^{3}$ para poder ver si se adapta a un parametro establecido. Las unidades de capacidad para líquidos en Grecia eran el kotylos $\left(273,5 \mathrm{~cm}^{3}\right)$ que cabe redondear en c. 270 $\mathrm{cm}^{3}$; el chous (12 kotyloi, $\left.3.282 \mathrm{~cm}^{3}\right)$ y el amphora (12 chous, 144 kotyloi, $39.390 \mathrm{~cm}^{3)}$ ) (Büsing, 1982, 28). En consecuencia, parece razonable que los 90 $\mathrm{cm}^{3}$ de capacidad de la Copa Kelin corresponden, con bastante aproximación, a 1/3 de kotylos de c. 273,5 $\mathrm{cm}^{3}$, a $1 / 36(12 \times 3)$ de chous y a $1 / 432(12 \times 12 \times 3)$ de amphora.

Al tratarse de una sola medida no se puede excluir que la capacidad de la copa fuera una coincidencia. Sin embargo, no parece que pudiera corresponder a algún otro patrón de medida de capacidad para líquidos, como el kotylos sirio-fenicio, peor conocido, y que se calcula en $c .350 \pm 33 \mathrm{~cm}^{3}$, pues no parece ofrecer relación con la copa de Kelin.

Por otra parte, como la copa imita una forma de la cerámica griega y ofrece una representación mítica que parece tener igual origen, es lógico suponer que la medida de capacidad para el vino que se bebiera en ella fuera también de origen helénico.

En conclusión, estos hechos, aunque de forma indirecta, parecen confirmar que la copa de Kelin ofrece una capacidad equivalente a $1 / 3$ de kotylos, la medida de capacidad para el vino en Grecia9.

Nos extraña la diferencia de color de sendas embarcaciones que no pueden enmarcarse dentro de lo que se considera una decoración bícroma. Una hipótesis sería una alusión al barco de la vida, el que se muestra con tono más claro, y al de la muerte, representada con el color más oscuro, y que se relacionaría también con los mitos dionisiacos y el consumo de vino como ritual funerario; pero también podríamos enmarcar el diseño en el momento de tránsito de la decoración de la cerámica griega entre las figuras negras y rojas. En este caso el artesano plasmaría esa dualidad en la coloración de los barcos. Con estas consideraciones y por los paralelos de esta forma cerámica (Page, 1984, 13) dataríamos la copa hacia mediados del s. IV a.C.

\section{CONCLUSIONES}

Los primeros testimonios de consumo de vino en la Meseta de Requena-Utiel son del s. VII a.C. y están documentados por las ánforas R1 que procedentes del sur peninsular se asocian a la colonización fenicia. No es un hecho destacable frente a otras zonas costeras donde estos testimonios están más presentes, pero debemos señalar la distancia que nos separa del mar y que estos primeros contactos propiciaron, pocos años después, un cultivo y una producción destacable. Hasta la actualidad la presencia de vitis vinifera en la comarca también es inferior a los testimonios existentes en otros yacimientos costeros, excavados durante años y cuyos estudios carpológicos han dado resultados de cultivo de vid (Pérez Jordá e Iborra Eres, 2011, 104).

La introducción del vino y de la vitis vinifera propiciaría la pronta elaboración dadas las características medioambientales de esta comarca tan favorables para el cultivo de la vid. La elección de la Solana de las Pilillas para ubicar este primer centro productor de vino se relacionaría con las condiciones óptimas del lugar. Por una parte los afloramientos calizos localizados en este sector que permitirían tallar los lagares y las terrazas fluviales para plantar los viñedos junto a la rambla, en un lugar soleado y bien protegido, y que haría que la uvas alcanzaran una graduación superior a las producidas en las zonas centrales de la meseta a una altitud más elevada y más desprotegidas.

Lo que primero llama la atención en las Pilillas, a pesar de haberse excavado solamente un sector del yacimiento, es su escala, las estructuras asociadas al lagar, las dimensiones de los muros y el trabajo invertido en la construcción de todo este complejo. De los cuatro lagares conservados, en una pisada se podrían extraer unos 2.000 litros de mosto que se trasegarían

\footnotetext{
9. Agradecemos la información sobre capacidades y otras sugerencias que amablemente nos hizo el Profesor Martín Almagro-Gorbea.
} 

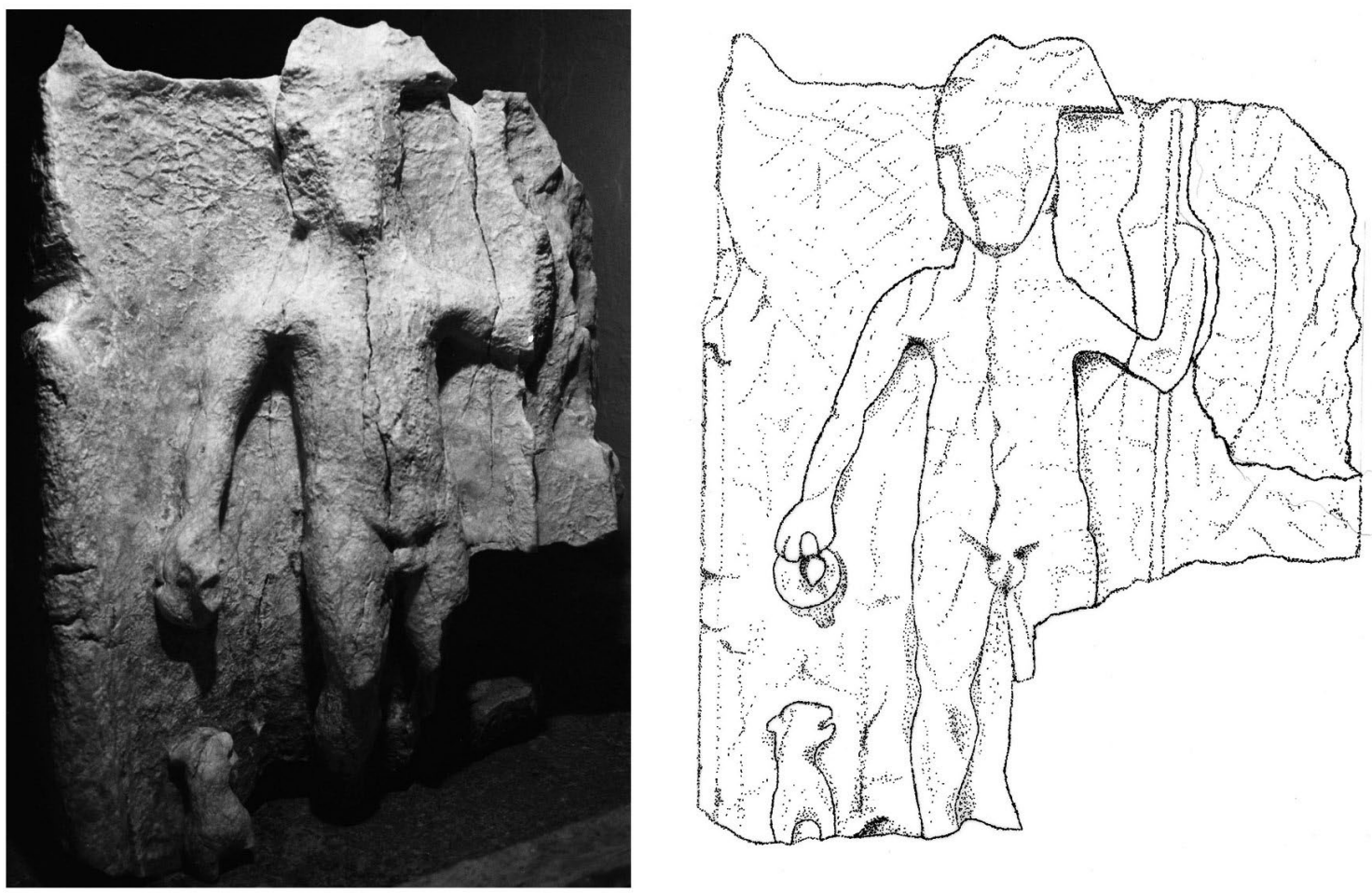

Figura 26: Relieve de Baco (Requena).

a las ánforas para su fermentación, lo que nos impide evaluar la cantidad de litros de vino que se producirían en una cosecha pero que, en todo caso, sería muy importante a juzgar por el número de lagares labrados. Destacamos también, que la producción de vino en las Pilillas estaba asociada a la elaboración de ánforas para la fermentación; de momento tenemos documentados tres tipos de ánforas de procedencia local de los siglos VI y V a.C., de tipologías diferentes, pero que han evolucionado a partir de los prototipos fenicios, presentes también en las Pilillas y que mantienen características de estas producciones. Solamente podemos afirmar con seguridad que uno de los tipos anfóricos fue elaborado en Casillas del Cura por lo que desconocemos si las otras ánforas recuperadas en Las Pilillas procederían de algún alfar más próximo, cuya localización desconocemos, o serían producciones de Casillas del Cura que todavia no hemos documentado.

En la actualidad se sigue trabajando en el complejo de Las Pilillas en donde, según los indicios que pueden apreciarse en superficie, tan solo se ha excavado de un 15 a un $20 \%$ de la superficie que suponemos tendría el yacimiento. En la última campaña se han recuperado en niveles de colmatación restos de ánforas fenicias procedentes del sur peninsular y cerámicas a mano del Hierro Antiguo en un pequeño sondeo por debajo del espacio que ocupó la bodega y que podrían indicar una ocupación del asentamiento a finales del s. VII.

El modelo de ocupación de Las Pilillas podría responder al definido como Granja-Torre (Brun, 2013, 31), bien documentado en otros lugares del mediterráneo y zonas peninsulares durante los siglos VII-VI a.C. (Moret, 2002) y que se vincula con un tipo de sociedad aristocrática que controlaría los sistemas de producción en un momento anterior a la formación de las ciudades (Quesada, 1994).

La elaboración del vino en los inicios del s. VI a.C. implicaría un dominio de la técnica que pensamos no tendría la población autóctona; los propios lagares rupestres o el uso de las prensas son un exponente de un sistema de producción presente en otros asentamientos mediterráneos de la misma cronología (Brun, 2004). Por todo esto pensamos que el complejo productor de vino de la Solana de las Pilillas estaría bajo influencia de gentes de origen fenicio-púnico que pudieron asesorar y quizás controlar un centro de primera magnitud en la elaboración y posterior comercialización del vino contando con mano de obra local que colaboraría en los trabajos previos a la elaboración, plantación, riego, poda, vendimia etc. (Vives Ferrandis, 2004).

El horno de Casillas del Cura es otro ejemplo de transmisión tecnológica que nos remite al mundo semita y que dada la relación con Las Pilillas permitiría intuir una organización del territorio en torno al río relacionada con la producción y comercio del vino. Las comunicaciones a través del llano, por lo que sería la Vereda Real, permitirían la salida de los productos tanto hacia la Meseta de Requena-Utiel como hacia Castilla-La Mancha, a través de Vadocañas, Pajazo, y otros pasos del Cabriel.

De momento poco se puede hablar de la elaboración de vino en los otros lagares de la rambla de la Alcantarilla donde solo se ha excavado el entorno de un 
lagar de capacidad aproximada de 250 litros y asociado a lo que podría haber sido una bodega o almacén de poca calidad constructiva de los ss. V y III a.C.; desconocemos los materiales asociados a este lagar, la forma de las ánforas, o si en los niveles del s. V se documentan producciones de Casillas del Cura. Todo parece indicar que el complejo de Las Pilillas generó una producción de vino que se extendió por el entorno, donde las condiciones físicas de estas ramblas permitían excavar lagares en roca y plantar viñedos, pero ya en algunos casos asociados a un poblamiento disperso y una sociedad con un patrón propio del Ibérico Pleno.

La temprana producción de vino en el yacimiento de las Pilillas fue el inicio de una "cultura del vino» que se perpetuó durante época ibérica y romana en la Meseta de Requena-Utiel. Un exponente podría ser la copa hallada en el entorno de Kelin que hemos presentado o el ara anepígrafa dedicada a Baco, recuperada en las proximidades de las Pilillas en el llano de Campo Arcís, asociada a un torcularium de un establecimiento rural de grandes dimensiones (Martínez Valle y Maronda, 2013) (Fig.26).

A los testimonios iconográficos citados hay que sumar la excavación de la pars rustica de una villa romana en el yacimiento del Batán, en las proximidades de Requena, donde se documentó un torcularium, con dos lagares de mampostería, las bases de los dolia in situ y un campo de vides asociado (Martínez Valle, en prensa). El hallazgo de tumbas antropomorfas por debajo del nivel de cimentación de los muros de la primera iglesia del s. XIII y extramuros del primitivo recinto islámico, en el solar que ocuparía posteriormente la Iglesia de San Nicolás es indicativo de población cristiana anterior a la islámica que ocuparía el promontorio de la Villa de Requena ${ }^{10}$ y que, lógicamente, elaboraría vino para sus celebraciones religiosas.

Los testimonios escritos de época medieval y moderna sobre vides y viticultura pueden consultarse en los documentos del Archivo Histórico de Requena donde se puede seguir la evolución de la viticultura desde finales de la Edad Media hasta la actualidad (Domingo, 2008; Lattorre, 2012, 155-174 y 213, 265-272).

Asunción Martínez Valle

Museo Municipal de Requena

Plaza Consistorial, 2

46340 Requena (Valencia)

museomunicipal@requena.es

10. En la excavación de la Iglesia de San Nicolás de Requena se ha documentado un importante conjunto de tumbas antropomorfas exentas de ajuar a las que se está realizando pruebas de datación por C14. La excavación ha estado dirigida por Asunción Martínez Valle, Lourdes Roca y Gustavo Nuñez.

\section{BIBLIOGRAFÍA}

ABAD, L. y SALA, F., 1993: El poblado ibérico de El Oral (San Fulgencio, Alicante), Serie Trabajos Varios del S.I.P. 90, Valencia.

ÁlVAREZ, N., CASTELlÓ, J. S. y GÓMEZ BELLARD, C., 2000: «Estudio preliminar de las ánforas del Alt de Benimaquía (Dénia, Alicante)», Quaderns de prehistòria i arqueologia de Castelló, 21, 121-136.

ANSON, L., 1976: Numismata Graeca: Greek coin-tipesclassified for immediate identification, Arnaldo Forni, Reedición facs. de la ed. de Londres 1910-1916, Bolonia

ARGILES, V. y SÁEZ, V., 2008: La Albosa requenense, Requena.

BADAL, E., BONET, H., COLLADO, E., FABADO, F. J., FUENTES, M., IZQUIERDO, I., MATA, C., MORENO, A., NTINOU, M., QUIXAL, D., RIPOLLÉS, P. P. y SORIA, L., 2010: Flora Ibérica. De lo real a lo imaginario, Serie Trabajos Varios 111, Valencia.

BONET ROSADO, H., 1995: El Tossal de San Miquel de Llíria. La antigua Edeta y su territorio, Valencia.

BONET, H., GARIBO, J., GUÉRIN, P., MATA, C., VALOR, J. y VIVES-FERRÁNDIZ, J., 2004: «Las ánforas importadas de las comarcas centrales del País Valenciano», Arqueo Mediterránia, 8, 203-227.

BRUN. J. P., 2004: Archéologie du vin et de l'huile de la Préhistoire à l'époque hellénistique, París.

BRUN, J. P., 2013: «Los origenes de la producción de vino», en A. MARTÍNEZ VALLE y C. PÉREZ (Eds.), Paisajes y Patrimonio Cultural del vino y de otras bebidas psicotrópicas, Conferencia Internacional TICCIH 2011, 23-33, Requena.

BÜSING, H., 1982: «Metrologische Beiträge», Jahrbuch des Deutschen Archäoologischen Instituts, 97, 1-45.

CASSON, L., 1994: Ships and Seafaring in ancient times, London.

CASTELLÓ, J. S., GÓMEZ BELLARD, C. y ÁlVAREZ, N., 2000: «Estudio preliminar de las ánforas del Alt de Benimaquía (Dénia, Alicante)», Quaderns de prehistòria i arqueologia de Castelló, 21, 121-136.

CELESTINO, S. y BLÁNQUEZ, J., 2007: «Origen y desarrollo del cultivo del vino en el Mediterráneo: La península ibérica», Universum, 22, 32-60.

DOMINGO IRANZO, E., 2008: El Fuero de Requena. Estudio crítico, trascripción, glosario, Requena.

DOMÍNGUEZ, A., 1998: «Las acuñaciones ibéricas y celtibéricas de la Hispania Citerior», en C. ALFARO ET ALII, Historia monetaria de Hispania antigua, 116-193, Madrid.

GÓMEZ BELLARD, C. y GUÉRIN, P., 1995: «Los lagares del Alt de Benimaquia (Denia): en los inicios del Vino Ibérico», S. CELESTINO (Ed.), Arqueología del vino. Los origenes del vino en Occidente, 241-270.

GORGUES, A., 2013: «La céramique tournée dans le domaine ibérique (VI-I siècle av. J.-C.). Une tecnologie sous influence?», Les transferts au premier millenaire av. J.-C. dans le sud-ouest de l'Europe, Mèlanges de la Casa de Velazquez. Nouvelle sèrie, 43 (1),111-139. 
JUAN-TRESSERAS, J. J. y MATAMALA, J. C., 2004: «Los contenidos de las ánforas en el Mediterráneo Occidental: primeros resultados», La circulació d'àmfores al Mediterrani occidental durant la Protohistòria (segles VIII-III a.C.): aspectes quantitatius i anàlisi de continguts, II Reunió Internacional d'Arqueología de Calafell, 283-292, Barcelona.

LATORRE, I., 2013: «El paisaje de la vid y el vino en la Meseta de Requena-Utiel (Valencia, España) desde la perspectiva de la documentación escrita», en A. MARTÍNEZ VALLE y C. PÉREZ (Eds.), Paisajes y Patrimonio Cultural del vino y de otras bebidas psicotrópicas, Conferencia Internacional TICCIH 2011, 265-272, Requena.

LATORRE, I., 2012: «El vino en Requena a través de las actas municipales: 1520-1550», La cultura del vino en la Meseta de Requena Utiel, V Congreso Comarcal, Oleana, 26, 155-174.

LORRIO, A. y SÁNCHEZ DEL PRADO, M. D., 2009: El Molón, Camporrobles, Valencia.

LORRIO, A. y SÁNCHEZ DEL PRADO, M. D., 2013: «El lagar ibérico del Molón (Camporrobles, Valencia)», Paisajes y Patrimonio Cultural del vino y de otras bebidas psicotrópicas, en A. MARTÍNEZ VALLE y C. PÉREZ (Eds.), Paisajes y Patrimonio Cultural del vino y de otras bebidas psicotrópicas, Conferencia Internacional TICCIH 2011, 159-168, Requena.

MALUQUER DE MOTES, J., 1965: «Una vasija excepcional del poblado ibérico de Mas Boscá», Pyrenae, 1, 129-138.

MARTÍNEZ GARCÍA, J. M., 1986: «Una cajita con decoración incisa del cerro de San Cristóbal (Sinarcas, Valencia)», Saguntum, 20, 103-116.

MARTÍNEZ VALLE, A., en prensa: «El Paisaje Cultural de la vid y el vino en la Denominación de Origen UtielRequena. Los yacimientos arqueológicos de las Pilillas y las Casillas del Cura», Instalaciones de campo para la elaboración de vino. Lagares, pilas y lagaretas. Paisaje y producción, (Labastida de Álava y San Vicente de la Sonsierra, Rioja, 2010).

MARTÍNEZ VALLE, A. y CASTELLANO, J. J., 1997: «Los hornos Ibéricos de las Casillas del Cura (Venta del Moro)», Recerques del Museu d'Alcoi, 6, 61-69.

MARTÍNEZ VALLE, A., CASTELLANO, J. J. y SÁEZ, A., 2000: «La producción de ánforas en el alfar ibérico de las Casillas del Cura (Venta del Moro, Valencia)», Ibers. Agricultors, artesans $i$ comerciants, Saguntum Extra 3, 225-230, Valencia.

MARTÍNEZ VALLE, A., CASTELLANO, J. J., SÁEZ, A., HORTELANO, L. y CUARTERO, F., 2001: «Los hornos ibéricos de las Casillas del Cura (Venta del Moro, Valencia)», en A. LORRIO (Ed.), Los íberos en la comarca de Requena-Utiel (Valencia), Anejo de la revista Lucentum 4, 135-150.

MARTÍNEZ VALLE, A. y HORTELANO, L., 2013: «Recipientes para el vino. Las producciones del alfar ibérico de las Casillas del Cura (Venta del Moro, Valencia)», en A. MARTÍNEZ VALLE y C. PÉREZ (Eds.), Paisajes y Patrimonio Cultural del vino y de otras bebidas psicotrópicas, Conferencia Internacional TICCIH 2011, 229-235, Requena.

MARTÍNEZ VALLE, A. y HORTELANO, L., 2012: «Ánforas vinarias de Casillas del Cura (Venta del Moro, Valencia) y la Solana de las Pilillas (Requena, Valencia). Caracterización, similitudes y diferencias», La cultura del vino en la Meseta de Requena Utiel, V Congreso Comarcal, Oleana, 26, 71-88, Requena,

MARTÍNEZ VALLE, A. y MARONDA, M. J., 2012: «La Solana de las Pilillas: Génesis de la viticultura en la Comarca de Requena-Utiel», La cultura del vino en la Meseta de Requena Utiel, $V$ Congreso Comarcal, Oleana, 26, 13-30, Requena.

MARTÍNEZ VALLE, A. y MARONDA, M. J., 2013: «Testimonios de viticultura durante la Antigüedad en la comarca de Requena-Utiel», Patrimonio cultural de la vid $y$ del vino (Almendralejo, 2011), 177-187, Badajoz.

MASCORT, Ma. T., SANMARTÍ, J. y SANTACANA, J., 1991: El jaciment protohistoric d'Aldovesta (Benifallet) $i$ el comerç fenici arcaic a la Cataluña Meridional, Tarragona.

MATA, C., 1991: Los Villares (Caudete de las Fuentes, Valencia): origen y evolución de la Cultura Ibérica, Serie Trabajos Varios del S.I.P. 88, Valencia.

MATA C., PÉREZ G., IBORRA M. P. y GRAU E., 1997: El vino de Kelin, Denominación de Origen Utiel-Requena, Valencia.

MATA C., 2006: «El ibérico antiguo de Kelin, los Villares (Caudete de las Fuentes, València) y el inicio de su organización territorial», De les comunitats locals als estats arcaics, III Reunió Internacional d'Arqueologia de Calafell, Arqueo Mediterrània, 9, 123-124.

MIRO. J., 1989: «Ánforas arcaicas en el litoral catalan. Un estudio acerca de las primeras importaciones de vino en Cataluña (650-500 a. C.)», Archivo Español de Arqueología, 62, 21-70.

MORENO MARTÍN, A., 2011: Cuando el paisaje se convierte en territorio: Aproximación al proceso de territorización íbero en la Plana d'Utiel, València (ss.VI-II ane), BAR Internacional, Series 2298.

MORET, P., 2002: «Tossal Montañes y La Gessera: ¿residencias aristocráticas del Ibérico Antiguo en la cuenca media del Matarraña?», Ilercavonia, 3, 65-73.

MUÑOZ, A., 1985: «Las ánforas preromanas de Cadiz», Anuario arqueológico de Andalucía, II, 471-478.

OLCINA, M., MARTÍNEZ, A, y SALA, F., 2009: «La Illeta dels Banyets (El Campello, Alicante). Época Ibérica y Romana I», Historia de la investigación y sintesis de las intervenciones recientes (2000-2003), Serie Mayor 7, Alicante.

PAGE, V., 1984: Imitaciones de influjo griego en la cerámica ibérica de Valencia, Alicante y Murcia, Iberia Graeca, Serie Arqueológica 1, Madrid.

PÉREZ BALLESTER, J., 2002: «Escenas con embarcaciones en la cerámica ibérica del Tossal de S. Miquel (Llíria, Valencia)», Cuadernos de Arqueología Marítima, 6, 279-297.

PÉREZ JORDÀ, G., 2000: «La conservación y la transformación de los productos agrícolas en el Mundo 
Ibérico»"», III Reunió sobre Economía en el Món Ibèric, Saguntum- PLAV Extra 3, 47-68, Valencia.

PÉREZ JORDÀ, G. e IBORRA ERES, P., 2011: «Aproximació a l'evolució econòmica al pais Valencià (ss. VII-II a.n.e.) a partir de les dades arqueobiològiques», Arqueo Mediterrània, 12.

PIQUERAS, J., 1997: La Meseta de Requena-Utiel, Requena.

PLA, E., 1980: Los Villares (Caudete de las Fuentes, Valencia), Serie de Trabajos Varios del SIP 68, Valencia.

POMEY, P., GIANNFROTTA, P. y NIETO, X., 1997: $L a$ Navigation dans l'Antiquité, Aix-en-Provence.

QUESADA, F., 1994: «Vino, aristocratas, tumbas y guerreros en la cultura ibérica (ss. V-II a. C.)», Verdolay, 6, 99-124.

QUIXAL, D., PÉREZ JORDÁ, G., MORENO, A. y MATA, C., 2012: «Origen y evolución de la vitivinicultura en la Meseta de Requena-Utiel entre los siglos VII a. C. - II d. C.», La cultura del vino en la Meseta de Requena Utiel, V Congreso Comarcal, Oleana, 26, 58-69.

RAMÓN TORRES, J., 1991: Las ánforas púnicas de Ibiza, Trabajos del Museo Arqueológico de Ibiza, 23.

RAMÓN TORRES, J., 1995: Las ánforas fenicio-púnicas del Mediterráneo central y occidental, Barcelona.

RIBERA, A., y TSANTINI, E., 2008: «Las ánforas del mundo ibérico», Cerámicas hispanorromanas: un estado de la cuestión, 617-634, Cádiz.
ROYO, J. I. y MINGUELL, J. A., 1992: «Restauración de materiales arqueológicos procedentes del Piquete de la Atalaya Azuara, Zaragoza», Arqueología Aragonesa 1990, 383-388, Zaragoza.

RUIZ, A. y MOLINOS, M., 1993: Los Iberos. Análisis arqueológico de un proceso histórico, Barcelona.

RUIZ PÉREZ, J. M., 2012: «Geomorfología y paisaje del entorno de la Solana de las Pilillas y ramblas de Los Morenos y Alcantarilla (Requena, Valencia)», La cultura del vino en la Meseta de Requena Utiel, V Congreso Comarcal, Oleana, 26, 31-56.

TORRES, J. B., 2000: «Focalización (punto de vista) en el Himno a Dioniso (H. Hom. VII)», Actas del X Congreso Español de Estudios Clásicos, tomo I, 651-6, Madrid.

TORRES, J. B., 2005: Himnos Homéricos, Madrid.

JUAN-TRESSERAS, J. J. y MATAMALA, J. C., 2004: «Los contenidos de las ánforas en el Mediterráneo Occidental: primeros resultados», La circulació d'àmfores al Mediterrani occidental durant la Protohistòria (segles VIII-III a.C.): aspectes quantitatius $i$ anàlisi de continguts, II Reunió Internacional d'Arqueología de Calafell, 283-292, Barcelona.

VIVES-FERRANDIS, J., 2004: «Tripodes, ánforas y consumo del vino: Acerca de la actividad comercial fenicia en la costa oriental de la Peninsula ibérica», Rivista di Studi Fenici, 32, 2, 9-33.

Recepción: 28-11-2013

Aceptación: 07-07-2014 